\title{
Bounds on the natural frequencies of laminated rectangular plates with extension-bending coupling.
}

Daokui $\mathrm{Li}^{1}$ and Christopher B. York ${ }^{2}$

Aerospace Sciences, University of Glasgow, James Watt (South) Building, Glasgow G12 8QQ, UK

\begin{abstract}
:
Extension-Bending coupling behaviour is believed to arise uniquely in anti-symmetric Cross-ply laminates. The results in this article serve to dispel this misconception by presenting solutions for both Cross-ply laminates and Standard laminates, defined as containing combinations of angle plies and cross plies, for a range of different sub-sequence symmetries. Details of the algorithm used to develop the definitive list of laminate stacking sequences with up to 21 plies are presented. Finally, natural frequency factor envelopes are developed, which identify significant differences in the bounds, across a range of aspect-ratios, between Standard laminate configurations and the previously assumed Cross-ply designs.
\end{abstract}

Keywords: A. Laminates; B. Vibration; B. Mechanical coupling; C. Laminate Mechanics.

\section{Introduction}

The use of laminated composite materials continues to expand at pace beyond traditional aerospace applications, and into other fields of advanced technology. This expansion is due, in part, to a growing awareness of the unique and largely unexploited thermo-mechanical properties that are a potential enabling technology if correctly tailored.

Buckling strength and natural frequency are important indices in the assessment of new and advanced laminate designs, and closed form solutions, which aid preliminary design for compression buckling strength and natural frequency prediction of simply supported rectangular plates are well known and well documented in the literature for both isotropic and uncoupled laminated composite materials [1-3]. Less well known are closed form solutions for coupled laminates, derived previously for so called antisymmetric Cross-ply laminates [4], possessing Extension-Bending coupling, and for anti-symmetric Angle-ply laminates, with Extension-Twisting and Shearing-Bending coupling [5,6]. This is perhaps due

\footnotetext{
${ }^{1}$ Permanent address: College of Aerospace Science and Engineering, National University of Defence Technology, Changsha, 410073, China. E: lidaokui@ nudt.edu.cn

${ }^{2}$ Corresponding author: Tel: +44 (0)141 3304345, E-mail address: Christopher.York@Glasgow.ac.uk
} 
to widespread misunderstanding of coupled laminate behaviour, highlighted by Leissa [7], where many buckling results have been presented on the false assumption that bifurcation buckling can occur, when in fact simply supported rectangular plates consisting of Cross-ply laminates with Extension-Bending coupling will bend, and not buckle, when subject to in-plane compressive load. This message appears to have gone unheeded by some [8]. Only the natural frequency predictions remain valid for this class of coupled laminate. However, given that Extension-Bending coupled laminates also require either special curved tooling or cold cure resin systems to achieve the desired shape after manufacture and remain subject to thermal distortions in service, this renders them functional rather than structural in nature. Misunderstanding of coupled laminates also extends to the widely held assumptions that ExtensionBending coupling is restricted to anti-symmetric, or more correctly, cross-symmetric Cross-ply laminates with even ply number groupings. Cross-ply laminates will be shown to represent only a subset of this class of coupled laminate; many configurations represent Standard laminates, defined as containing combinations of both cross-plies and angle-plies. This is an important discovery, particularly if the larger design space leads to a significant change in the bounds on the natural frequencies.

In this article therefore, definitive listings of laminate configurations with Extension-Bending coupling are derived for up to 21 plies, to complement previous studies on other laminate classes. All plies are assumed to possess identical fibre-matrix properties, e.g. carbon-epoxy or glass-epoxy, etc., with constant thickness throughout, differing only by their orientations. The listings comprise individual stacking sequences, separated into Cross-ply laminates, representing the generally assumed (anti-symmetric) form for this class of laminate, and Standard laminates, deemed to represent laminates containing cross ply and angle ply combinations with standard orientations, i.e., 90 and/or $0,+45,-45^{\circ}$. In both cases, no constraint is imposed on the form of sub-sequence symmetry.

The stacking sequences are given in symbolic form since the angle-plies (+/-) can in fact be assigned any arbitrary orientation, $0<\theta<90^{\circ}$, and the cross-plies $\left(O / O\right.$, representing $\left.0^{\circ} / 90^{\circ}\right)$ can be interchanged. Each stacking sequence is presented together with a set of non-dimensional parameters, derived in Section 2, from which the laminate stiffness properties can be readily determined for any fibre-matrix system.

Section 3 presents the relevant background theory and the derivation of the closed form solution used to calculate the natural frequency results that then follow. Section 4 presents the frequency bounds for both 
Standard and Cross-ply laminates. These comparisons involve the upper- and lower-bounds on the first three natural frequencies for Extension-Bending coupled laminates, over a broad range of aspect-ratios.

\section{Extension-Bending coupled laminates.}

\subsection{Laminate Characterisation.}

Laminated composite materials have recently been characterized [9] in terms of their response to mechanical and/or thermal loading, to help understand coupling behaviour not present in conventional materials. Equation (1) describes the well-known ABD relation from classical lamination theory, relating force $\{\mathbf{N}\}$ and moment $\{\mathbf{M}\}$ resultants with in-plane strains $\{\boldsymbol{\varepsilon}\}$ and curvatures $\{\mathbf{\kappa}\}$, and from which the coupling behaviour is, by inspection, dependent on the form of the elements, $A_{i j}, B_{i j}$ and $D_{i j}$, of the extensional [A], coupling [B] and bending [D] stiffness matrices, respectively:

$$
\begin{aligned}
& \left\{\begin{array}{l}
N_{x} \\
N_{y} \\
N_{x y}
\end{array}\right\}=\left[\begin{array}{lll}
\mathrm{A}_{11} & \mathrm{~A}_{12} & \mathrm{~A}_{16} \\
& \mathrm{~A}_{22} & \mathrm{~A}_{26} \\
\text { Sym. } & & \mathrm{A}_{66}
\end{array}\right]\left\{\begin{array}{l}
\varepsilon_{x} \\
\left.\varepsilon_{y}\right\} \\
\tau_{x y}
\end{array}\right\}+\left[\begin{array}{lll}
\mathrm{B}_{11} & \mathrm{~B}_{12} & \mathrm{~B}_{16} \\
& \mathrm{~B}_{22} & \mathrm{~B}_{26} \\
\text { Sym. } & & \mathrm{B}_{66}
\end{array}\right]\left\{\begin{array}{l}
\kappa_{x} \\
\left.\kappa_{y}\right\} \\
\kappa_{x y}
\end{array}\right\} \\
& \left\{\begin{array}{l}
M_{x} \\
M_{y} \\
M_{x y}
\end{array}\right\}=\left[\begin{array}{lll}
\mathrm{B}_{11} & \mathrm{~B}_{12} & \mathrm{~B}_{16} \\
& \mathrm{~B}_{22} & \mathrm{~B}_{26} \\
\text { Sym. } & & \mathrm{B}_{66}
\end{array}\right]\left\{\begin{array}{l}
\varepsilon_{x} \\
\varepsilon_{y} \\
\tau_{x y}
\end{array}\right\}+\left[\begin{array}{lll}
\mathrm{D}_{11} & \mathrm{D}_{12} & \mathrm{D}_{16} \\
& \mathrm{D}_{22} & \mathrm{D}_{26} \\
\text { Sym. } & & \mathrm{D}_{66}
\end{array}\right]\left\{\begin{array}{l}
\kappa_{x} \\
\kappa_{y} \\
\kappa_{x y}
\end{array}\right\}
\end{aligned}
$$

The coupling behaviour can be described by a shorthand notation, using an extended subscript notation defined previously by the Engineering Sciences Data Unit [10]. Cross-symmetric Cross-ply laminates are referred to by the designation $\mathbf{A}_{\mathrm{S}} \mathbf{B}_{l} \mathbf{D}_{\mathrm{S}}$, signifying that the extensional stiffness matrix $[\mathbf{A}]$ is Simple in nature, i.e., uncoupled, since

$\mathrm{A}_{16}=\mathrm{A}_{26}=0$

the coupling matrix $\left[\mathbf{B}_{l}\right]$ has non-zero leading-diagonal elements, i.e.,

$\mathrm{B}_{11}, \mathrm{~B}_{22} \neq 0$,

with all other elements zero and; the bending stiffness matrix $\left[\mathbf{D}_{\mathrm{S}}\right]$ is Simple in nature, i.e., uncoupled, since

$\mathrm{D}_{16}=\mathrm{D}_{26}=0$

Alternatively, coupled laminates may also be described in terms of the response that they exhibit under various combinations of force and moment resultants (or equally, the force and moment resultants that arise from enforced strains or curvatures), using a cause-effect relationship. Cross-symmetric Cross-ply 
laminates may therefore be described as $\underline{E-B}$ laminates, since Extension $(E)$ causes a Bending $(B)$ effect. Each cause-effect pair is reversible, e.g. $\underline{B-E}$. Note that this response-based labelling is complementary to the Engineering Sciences Data Unit subscript notation [10].

\subsection{Derivation of Extension-Bending coupled laminates.}

This section describes the derivation of two definitive listings of laminate stacking sequences and associated non-dimensional parameters, from which the stiffness properties are readily derived for any fibre/matrix system.

In the derivation of the stacking sequences for laminates with Extension-Bending coupling, it has been assumed that all plies have identical material properties and thickness, $t$, and differ only with respect to ply orientation.

The general rules of symmetry are relaxed. Stacking sequences are presented in symbolic form to allow for non-standard ply orientations, although, all natural frequency results presented relate to standard ply angle orientations, $\pm 45,0$ and $90^{\circ}$. For Standard laminates, all stacking sequences have an angle-ply $(+)$ on one surface $\left(1^{\text {st }}\right.$ ply $)$ of the laminate, but the other surface ply may have equal $(+)$ or opposite $(-)$ orientation or it may indeed be a cross ply ( $\mathrm{O}$ or $)$ of 0 or $90^{\circ}$ orientation. This constraint prevents the development of Cross-ply laminates, i.e., those containing cross plies only. For Cross-ply laminates, the constraint of one outer surface cross ply $(\mathrm{O})$ is applied to avoid duplicate stacking sequences when cross plies are exchanged, 0 with $90^{\circ}$ and vice versa.

Non-dimensional parameters are developed to allow for any fiber/matrix system. The derivation of nondimensional stiffness parameters is readily demonstrated for the example of a 9-ply laminate, with antisymmetric angle plies and non-symmetric cross plies: $[+/-/ O /-/ / /+/ /+/-]_{\mathrm{T}}$, using the well-known stiffness relationships:

$\mathrm{A}_{\mathrm{ij}}=\Sigma \mathrm{Q}_{\mathrm{ij}, k}^{\prime}\left(z_{k}-z_{k-1}\right), \mathrm{B}_{\mathrm{ij}}=\Sigma \mathrm{Q}_{\mathrm{ij}, k}^{\prime}\left(z_{k}^{2}-z_{k-1}^{2}\right) / 2$ and $\mathrm{D}_{\mathrm{ij}}=\Sigma \mathrm{Q}_{\mathrm{ij}, k}^{\prime}\left(z_{k}^{3}-z_{k-1}^{3}\right) / 3$

where the summation may instead be written in sequence order for the $(k=1,2, . .)$,9 individual plies, and where $z$, representing the distance from the laminate mid-plane, is expressed here in terms of the uniform ply thickness, $t$, see Fig. 1. For the coupling stiffness matrix:

$\mathrm{B}_{\mathrm{ij}}=\left\{\mathrm{Q}_{\mathrm{ij}+}^{\prime}\left((-7 t / 2)^{2}-(-9 t / 2)^{2}\right)+\mathrm{Q}_{\mathrm{ij}-}^{\prime}\left((-5 t / 2)^{2}-(-7 t / 2)^{2}\right)+\mathrm{Q}^{\prime}{ }_{\mathrm{ij}} \mathrm{o}\left((-3 t / 2)^{2}-(-5 t / 2)^{2}\right)\right.$ 
$+\mathrm{Q}_{\mathrm{ij}-}^{\prime}\left((-t / 2)^{2}-(-3 t / 2)^{2}\right)+\mathrm{Q}_{\mathrm{ij} \boldsymbol{\bullet}}^{\prime}\left((t / 2)^{2}-(-t / 2)^{2}\right)+\mathrm{Q}_{\mathrm{ij}+}^{\prime}\left((3 t / 2)^{2}-(t / 2)^{2}\right)$

$\left.+\mathrm{Q}_{\mathrm{ij} \bullet}^{\prime}\left((5 t / 2)^{2}-(3 t / 2)^{2}\right)+\mathrm{Q}_{\mathrm{ij}+}^{\prime}\left((7 t / 2)^{2}-(5 t / 2)^{2}\right)+\mathrm{Q}_{\mathrm{ijj}}^{\prime}\left((9 t / 2)^{2}-(7 t / 2)^{2}\right)\right\} / 2$

and the transformed reduced stiffness $\mathrm{Q}_{\mathrm{ij}}^{\prime}$, with subscripts $\mathrm{i}, \mathrm{j}=1,2,6$, corresponds to the orientation of ply $k$.

The coupling stiffness contributions for each ply orientation may be summarised as:

$\mathrm{B}_{\mathrm{ij}+}=0 t^{2} / 2 \times \mathrm{Q}_{\mathrm{ij}+}^{\prime}=\chi_{+} t^{2} / 4 \times \mathrm{Q}_{\mathrm{ij}+}^{\prime}$

$\mathrm{B}_{\mathrm{ij}-}=0 t^{2} / 2 \times \mathrm{Q}_{\mathrm{ij}-}^{\prime}=\chi_{-} t^{2} / 4 \times \mathrm{Q}_{\mathrm{ij}-}^{\prime}$

$\mathrm{B}_{\mathrm{ij} \mathrm{O}}=-4 t^{3} / 2 \times \mathrm{Q}_{\mathrm{ij} \mathrm{O}}^{\prime}=\chi_{\mathrm{O}} t^{2} / 4 \times \mathrm{Q}_{\mathrm{ij} \mathrm{O}}^{\prime}$

$\mathrm{B}_{\mathrm{ij} \bullet}=4 t^{3} / 2 \times \mathrm{Q}_{\mathrm{ijo}_{\mathrm{O}}}^{\prime}=\chi_{\mathrm{o}} t^{2} / 4 \times \mathrm{Q}_{\mathrm{ij} \mathrm{O}}^{\prime}$

where the non-dimensional parameters $\chi_{\odot}=-8, \chi_{\bullet}=8$ and $\chi_{+}=\chi_{-}=0$.

Note that these non-dimensional parameters allow an assessment of the relative coupling magnitude, against the maximum possible within each ply number grouping, $n$ :

$\chi_{\max }=n^{2}=\left|\chi_{0}\right|+\left|\chi_{\bullet}\right|$

where $\chi_{\max }$ can be achieved only by cross-symmetric cross-ply laminates of the form $\left[\mathrm{O}_{n / 2} / \mathbf{\bullet}_{n / 2}\right]_{\mathrm{T}}$.

Non-dimensional parameters can be developed for the extensional and bending stiffness matrices in the same way. However, the procedure is more conveniently demonstrated in tabular form, as in Table 1, where the first two columns provide the ply number and orientation, respectively. Subsequent columns illustrate the summations, for each ply orientation, of $\left(z_{k}-z_{k-1}\right),\left(z_{k}^{2}-z_{k-1}^{2}\right)$ and $\left(z_{k}^{3}-z_{k-1}^{3}\right)$, relating to the $\mathbf{A}, \mathbf{B}$ and $\mathbf{D}$ matrices, respectively.

The non-dimensional parameters arising from the summations for the A, B and D matrices are: $n_{\bigcirc}(=$ $\left.{ }_{\mathrm{A}} \Sigma_{\mathrm{O}}\right)=1, n_{\bullet}=2, n_{-}=3$ and $n_{+}=3 ; \chi_{\bigcirc}\left(=2 \times{ }_{\mathrm{B}} \Sigma_{\mathrm{O}}\right)=-8, \chi_{\bullet}=8$ and $\chi_{-}=\chi_{+}=0$ and; $\zeta_{\mathrm{O}}\left(=4 \times{ }_{\mathrm{D}} \Sigma_{\mathrm{O}}\right)=49$, $\zeta_{\bullet}=50, \zeta_{-}=315$ and $\zeta_{+}=315$, where $\zeta=\zeta_{\bigcirc}+\zeta_{\bullet}+\zeta_{-}+\zeta_{+}=n^{3}=9^{3}=729$.

These non-dimensional parameters, together with the transformed reduced stiffness, $\mathrm{Q}_{\mathrm{ij}}^{\prime}$, for each ply orientation with constant ply thickness, $t$, facilitate simple calculation of the elements of the extensional, coupling and bending stiffness matrices from:

$$
\begin{aligned}
& \mathrm{A}_{\mathrm{ij}}=\left\{n_{+} \mathrm{Q}_{\mathrm{ij}+}^{\prime}+n_{-} \mathrm{Q}_{\mathrm{ij}-}^{\prime}+n_{\mathrm{O}} \mathrm{Q}_{\mathrm{ij} \mathrm{O}}^{\prime}+n_{\bullet} \mathrm{Q}_{\mathrm{ij} \bullet}^{\prime}\right\} t \\
& \mathrm{~B}_{\mathrm{ij}}=\left\{\chi_{+} \mathrm{Q}_{\mathrm{ij}+}^{\prime}+\chi_{-} \mathrm{Q}_{\mathrm{ij}-}^{\prime}+\chi_{\odot} \mathrm{Q}_{\mathrm{ij},}^{\prime}+\chi_{\bullet} \mathrm{Q}^{\prime}{ }_{\mathrm{ij}}\right\} t^{2} / 4 \\
& \mathrm{D}_{\mathrm{ij}}=\left\{\zeta_{+} \mathrm{Q}_{\mathrm{ijj}+}^{\prime}+\zeta_{-} \mathrm{Q}_{\mathrm{ij}-}^{\prime}+\zeta_{\mathrm{O}} \mathrm{Q}_{\mathrm{ijo}}^{\prime}+\zeta_{\bullet} \mathrm{Q}_{\mathrm{ij} \bullet}^{\prime}\right\} t^{3} / 12
\end{aligned}
$$


The transformed reduced stiffness relationships are defined by:

$\mathrm{Q}^{\prime}{ }_{11}=\mathrm{Q}_{11} \cos ^{4} \theta+2\left(\mathrm{Q}_{12}+2 \mathrm{Q}_{66}\right) \cos ^{2} \theta \sin ^{2} \theta+\mathrm{Q}_{22} \sin ^{4} \theta$

$\mathrm{Q}_{12}^{\prime}=\mathrm{Q}_{21}^{\prime}=\left(\mathrm{Q}_{11}+\mathrm{Q}_{22}-4 \mathrm{Q}_{66}\right) \cos ^{2} \theta \sin ^{2} \theta+\mathrm{Q}_{12}\left(\cos ^{4} \theta+\sin ^{4} \theta\right)$

$\mathrm{Q}_{16}^{\prime}=\mathrm{Q}_{61}^{\prime}=\left\{\left(\mathrm{Q}_{11}-\mathrm{Q}_{12}-2 \mathrm{Q}_{66}\right) \cos ^{2} \theta+\left(\mathrm{Q}_{12}-\mathrm{Q}_{22}+2 \mathrm{Q}_{66}\right) \sin ^{2} \theta\right\} \cos \theta \sin \theta$

$\mathrm{Q}_{22}^{\prime}=\mathrm{Q}_{11} \sin ^{4} \theta+2\left(\mathrm{Q}_{12}+2 \mathrm{Q}_{66}\right) \cos ^{2} \theta \sin ^{2} \theta+\mathrm{Q}_{22} \cos ^{4} \theta$

$\mathrm{Q}_{26}^{\prime}=\mathrm{Q}_{62}^{\prime}=\left\{\left(\mathrm{Q}_{11}-\mathrm{Q}_{12}-2 \mathrm{Q}_{66}\right) \sin ^{2} \theta+\left(\mathrm{Q}_{12}-\mathrm{Q}_{22}+2 \mathrm{Q}_{66}\right) \cos ^{2} \theta\right\} \cos \theta \sin \theta$

$\mathrm{Q}_{66}^{\prime}=\left(\mathrm{Q}_{11}+\mathrm{Q}_{22}-2 \mathrm{Q}_{12}-2 \mathrm{Q}_{66}\right) \cos ^{2} \theta \sin ^{2} \theta+\mathrm{Q}_{66}\left(\cos ^{4} \theta+\sin ^{4} \theta\right)$

and the reduced stiffness terms are calculated from the material properties:

$\mathrm{Q}_{11}=\mathrm{E}_{1} /\left(1-\mathrm{v}_{12} \mathrm{v}_{21}\right)$

$\mathrm{Q}_{12}=v_{12} \mathrm{E}_{2} /\left(1-v_{12} v_{21}\right)$

$\mathrm{Q}_{22}=\mathrm{E}_{2} /\left(1-\mathrm{v}_{12} \mathrm{v}_{21}\right)$

$\mathrm{Q}_{66}=\mathrm{G}_{12}$

The Extension-Bending coupled laminate class can be developed by filtering a given set of stacking sequences through the following non-dimensional parameter constraints:

$n_{+}=n_{-}$

$\chi_{+}=\chi_{-}=0$

$\chi_{0}=-\chi_{\bullet} \neq 0$

$\zeta_{+}=\zeta_{-}$

A proof for these constraints is provided in the Electronic Annex to this article. Table 2 provides details of the numbers of unique solutions for Extension-Bending coupled laminates, arising from the parameter constraints of Eq. (12), for Standard and Cross-ply laminates, respectively, across the range of ply number groupings investigated, i.e. $n=2-21$.

Abridged stacking listings, including non-dimensional parameters are given for 12-layer Standard and Cross-ply $\underline{E-B}$ laminates in Tables 3 and 4, respectively. The stacking sequences are ranked in order of Extension-Bending coupling magnitude, $\chi_{\circ}$, and then by order of bending stiffness magnitude, $\zeta_{\circ}$.

Extension-Bending coupled designs are synonymous with anti-symmetric Cross-ply laminates in the literature. However, Tables 3 and 4 demonstrate that a description of the stacking sequence symmetry offers no reliable indication of the likely laminate behavior. For example, from the abridged results in 
Tables 3, representing the $72 \underline{E-B}$ coupled solutions derived for 12-ply Standard laminates, 20 have antisymmetric angle plies and cross-symmetric cross plies, e.g. Ref. 24 : $[+/-/-/+/ \bigcirc / \bigcirc / \bigcirc / / /-/+/+/-]_{\mathrm{T}}, 40$ have anti-symmetric angle plies and non-symmetric cross plies, e.g. Ref. 28: $[+/-/-/+/ O / O / O / O /-/+/+/-]_{\mathrm{T}}, 4$ have symmetric angle plies and cross-symmetric cross plies, e.g. Ref. 15: $[+/-/-/ O /+/ O / O /+/ / /-/-/+]_{\mathrm{T}}$, and the remaining 8 have symmetric angle plies and non-symmetric cross plies, e.g. Ref. 21 : $[+/-/-/ O /+/ \bigcirc / \bigcirc /+/ \bigcirc /-/-/+]_{\mathrm{T}}$. Similarly, of the 1,979 Cross-ply laminates, only 31 are cross-symmetric; the others are non-symmetric. Indeed, fully uncoupled laminates may have

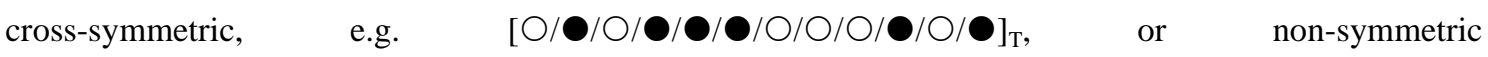

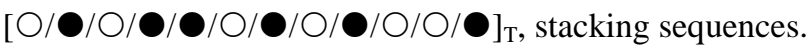

\section{Background theory on plate vibration for coupled laminates.}

The equilibrium equations for the vibration of a laminated plate with Extension-Bending $(\underline{E-B})$ coupling are:

$$
\begin{aligned}
& \partial \mathrm{N}_{\mathrm{x}} / \partial \mathrm{x}+\partial \mathrm{N}_{\mathrm{xy}} / \partial \mathrm{y}=0 \\
& \partial \mathrm{N}_{\mathrm{xy}} / \partial \mathrm{x}+\partial \mathrm{N}_{\mathrm{y}} / \partial \mathrm{y}=0 \\
& \partial^{2} \mathrm{M}_{\mathrm{x}} / \partial \mathrm{x}^{2}+2 \partial^{2} \mathrm{M}_{\mathrm{xy}} / \partial \mathrm{x} \partial \mathrm{y}+\partial^{2} \mathrm{M}_{\mathrm{y}} / \partial \mathrm{y}^{2}=\rho \partial^{2} \mathrm{w} / \partial \mathrm{t}^{2}
\end{aligned}
$$

Here, $\rho$ is the mass per mid-plane area. The force and moment resultants are related to the mid-plane strains $\{\boldsymbol{\varepsilon}\}=\left\{\varepsilon_{x}, \varepsilon_{x}, \gamma_{x y}\right\}=\{\partial \mathrm{u} / \partial \mathrm{x}, \partial \mathrm{v} / \partial \mathrm{y}, \partial \mathrm{u} / \partial \mathrm{y}+\partial \mathrm{v} / \partial \mathrm{x}\}$ and curvatures $\{\mathbf{\kappa}\}=\left\{\kappa_{x}, \kappa_{x}, \kappa_{x y}\right\}=\left\{\partial^{2} \mathrm{w} / \partial \mathrm{x}^{2}\right.$, $\partial^{2} w / \partial y^{2}, 2 \partial^{2} w / \partial x \partial y$ \} through the ABD relation of Eq. (1), in which, $u, v$ and $w$ are the middle-surface displacements in the $\mathrm{x}, \mathrm{y}$ and $\mathrm{z}$ directions, respectively. Equations (13) can be expressed in terms of these mid-plane displacements as:

$$
\begin{aligned}
& \mathrm{A}_{11} \partial^{2} \mathrm{u} / \partial \mathrm{x}^{2}+\mathrm{A}_{66} \partial^{2} \mathrm{u} / \partial \mathrm{y}^{2}+\left(\mathrm{A}_{12}+\mathrm{A}_{66}\right) \partial^{2} \mathrm{v} / \partial \mathrm{x} \partial \mathrm{y}-\mathrm{B}_{11} \partial^{3} \mathrm{w} / \partial \mathrm{x}^{3}=0 \\
& \left(\mathrm{~A}_{12}+\mathrm{A}_{66}\right) \partial^{2} \mathrm{u} / \partial \mathrm{x} \partial \mathrm{y}+\mathrm{A}_{66} \partial^{2} \mathrm{v} / \partial \mathrm{x}^{2}+\mathrm{A}_{22} \partial^{2} \mathrm{v} / \partial \mathrm{y}^{2}-\mathrm{B}_{22} \partial^{3} \mathrm{w} / \partial \mathrm{y}^{3}=0 \\
& \mathrm{D}_{11} \partial^{4} \mathrm{w} / \partial \mathrm{x}^{4}+2\left(\mathrm{D}_{12}+2 \mathrm{D}_{66}\right) \partial^{4} \mathrm{w} / \partial \mathrm{x}^{2} \partial \mathrm{y}^{2}+\mathrm{D}_{22} \partial^{4} \mathrm{w} / \partial \mathrm{y}^{4}-\mathrm{B}_{11} \partial^{3} \mathrm{u} / \partial \mathrm{x}^{3}-\mathrm{B}_{22} \partial^{3} \mathrm{v} / \partial \mathrm{y}^{3}+\rho \partial^{2} \mathrm{w} / \partial \mathrm{t}^{2}=0
\end{aligned}
$$

The free vibration of an elastic plate is harmonic in time, so for an $\underline{E-B}$ laminated rectangular plate (with length $a \times$ width $b$ ) under so called $S 2$ simply supported boundary conditions [8], which constrain inplane extension and remove the possibility of induced extension-bending coupling, mid-plane displacements are of the form: 
$\mathrm{u}=\mathrm{U} \cos (\mathrm{m} \pi x / a) \sin (\mathrm{n} \pi x / b) \mathrm{e}^{i \omega t}$

$$
\mathrm{v}=\mathrm{V} \sin (\mathrm{m} \pi x / a) \cos (\mathrm{n} \pi x / b) \mathrm{e}^{i \omega t}
$$

$\mathrm{W}=\mathrm{W} \sin (\mathrm{m} \pi x / a) \sin (\mathrm{n} \pi x / b) \mathrm{e}^{i \omega t}$

which satisfy the boundary conditions and equilibrium equations if the circular natural frequency:

$\omega^{2}=\left(\pi^{4} / \rho\right)\left\{\mathrm{T}_{33}+\left(2 \mathrm{~T}_{12} \mathrm{~T}_{23} \mathrm{~T}_{13}-\mathrm{T}_{22} \mathrm{~T}_{13}{ }^{2}-\mathrm{T}_{11} \mathrm{~T}_{23}{ }^{2}\right) /\left(\mathrm{T}_{11} \mathrm{~T}_{22}-\mathrm{T}_{12}{ }^{2}\right)\right\}$

where

$$
\begin{array}{ll}
\mathrm{T}_{11}=\mathrm{A}_{11}(\mathrm{~m} \pi / a)^{2}+\mathrm{A}_{66}(\mathrm{n} \pi / b)^{2} & \mathrm{~T}_{12}=\left(\mathrm{A}_{12}+\mathrm{A}_{66}\right)(\mathrm{m} \pi / a)(\mathrm{n} \pi / b) \quad \mathrm{T}_{13}=-\mathrm{B}_{11}(\mathrm{~m} \pi / a)^{3} \\
\mathrm{~T}_{22}=\mathrm{A}_{22}(\mathrm{n} \pi / b)^{2}+\mathrm{A}_{66}(\mathrm{~m} \pi / a)^{2} & \mathrm{~T}_{23}=-\mathrm{B}_{22}(\mathrm{n} \pi / b)^{3} \\
\mathrm{~T}_{33}=\mathrm{D}_{11}(\mathrm{~m} \pi / a)^{4}+2\left(\mathrm{D}_{12}+2 \mathrm{D}_{66}\right)(\mathrm{m} \pi / a)^{2}(\mathrm{n} \pi / b)^{2}+\mathrm{D}_{22}(\mathrm{n} \pi / b)^{4}
\end{array}
$$

\section{Natural frequency Results.}

This section presents bounds on the natural frequencies of $\underline{E-B}$ coupled Cross-ply laminates (with crosssymmetric and non-symmetric configurations) and laminates containing standard ply orientations. Due to the substantial number of laminate solutions found, from which upper- and lower-bound natural frequencies envelopes are now derived, the closed form solution of Eq. (16) has been incorporated into a computer code in which the non-dimensional parameters for each stacking sequence, derived in Section 2 , are read and a series of natural frequency factor calculations performed over a range of aspect-ratios. Such a study would not be possible with a commercial analysis code, but checks using the MSC/NASTRAN ${ }^{\circledR}$ finite element code have been performed to ensure that the results presented here are validated.

\subsection{Benchmark results.}

Table 5 gives the fundamental natural frequency factor results for $\underline{E-B}$ coupled Cross-ply laminates with assumed material properties: $\mathrm{E}_{1} / \mathrm{E}_{2}=40, \mathrm{G}_{12} / \mathrm{E}_{2}=0.5$ and $v=0.25$. The frequency factor results, $\Omega^{\prime}$, from Jones [4], are first matched against those calculated with MSC/NASTRAN ${ }^{\circledR}$, where the repeating cross-symmetric Cross-ply laminate $\left[(0 / 90)_{n / 2}\right]_{\mathrm{T}}$, or $[0 / 90 / \ldots . . . / 0 / 90]_{\mathrm{T}}$, was assumed, i.e., the form synonymous with the $\underline{E-B}$ coupled laminates, where $n=2,4,6$ and $\infty$ in the stacking sequence definition and represents the total number of plies; an infinite number of repetitions of the alternating plies converges on the fully uncoupled laminate.

The total thickness of laminate was set to $H=b / 1000$ to eliminate the effects of shear deformation in the 
MSC/NASTRAN ${ }^{\circledR}$ modelling. A converged mesh was achieved using 6400 QUAD4 elements for plate aspect-ratio $a / b=1$; and modified for each aspect-ratio investigated to maintain a consistent mesh density. Note that the form of the non-dimensional frequency factor generally used $[4,8]$ :

$\Omega^{\prime}=\omega a^{2} / \pi^{2} \sqrt{ }\left(\rho / \mathrm{D}_{22}\right)$

is appropriate only for the comparison of laminates containing repeating pairs of cross-symmetric cross-

plies. This non-dimensional form is inappropriate for the new results presented here, due to mismatches in bending stiffness contribution in laminates with 2, 3 or 4 ply orientations and/or different forms of stacking sequence symmetry. For this reason, the following equation is used to present the nondimensional results throughout this article:

$\Omega=\omega b^{2} / \pi^{2} \sqrt{ }\left(\rho / \mathrm{D}_{\text {Iso }}\right)$

where the flexural rigidity, $\mathrm{D}_{\text {Iso }}$, for the equivalent isotropic laminate of thickness $H$, is given in terms of the reduced stiffness properties, $Q_{\mathrm{ij}}$, defined in Eq. (11), as:

$\mathrm{D}_{\text {Iso }}=\left\{3 \mathrm{Q}_{11}+3 \mathrm{Q}_{22}+2 \mathrm{Q}_{12}+4 \mathrm{Q}_{66}\right\} H^{3} / 96$

The final two columns of Table 5 give the fundamental natural frequency factor results, derived from Eq. (16), for the upper- and lower-bounds of each ply number grouping, $n$, corresponding to the new Crossply laminates derived in Section 2. The $2^{\text {nd }}$ and $3^{\text {rd }}$ natural frequency comparisons are given in Tables 6 and 7 , respectively.

Tables $5-7$ demonstrate that the repeating cross-symmetric Cross-ply laminate, $\left[(0 / 90)_{n / 2}\right]_{\mathrm{T}}$, represents neither an upper-bound nor a lower-bound solution on the design space for Cross-ply laminates, except for the lowest ply number groupings, where it represents both when it is the only solution $(n=2)$ or the upper-bound when it represents one of only 6 solutions $(n=4)$.

\subsection{New laminate design comparisons.}

Figure 2(a) illustrates the fundamental natural frequency factor envelopes for Cross-ply laminates for the entire range of ply number groupings developed in Section 2, with labels $\mathrm{C} 2{ }^{\mathrm{L}}-\mathrm{C} 21^{\mathrm{L}}$ and $\mathrm{C} 2{ }^{\mathrm{U}}-\mathrm{C} 21^{\mathrm{U}}$, for the lower- and upper-bound envelopes, respectively, of each ply number grouping in Table 2. Note that $\mathrm{C} 2{ }^{\mathrm{L}}$ and $\mathrm{C} 2{ }^{\mathrm{U}}$ correspond to a single laminate solution and are therefore the same curve. These can be compared with the corresponding Standard laminates in Fig. 2(b), with labels $\mathrm{S} 9^{\mathrm{L}}-\mathrm{S} 21^{\mathrm{L}}$ and $\mathrm{S} 9^{\mathrm{U}}-\mathrm{S} 21^{\mathrm{U}}$. Envelopes for the equivalent Fully Isotropic Laminate, or FIL, are superimposed for comparison, since 
they are always bounded by the upper- and lower-bound curves for Standard laminates, except in the case of $n=9$ and 10, due to the limited number of solutions in these ply number groupings. However, no similar trend is observed in the Cross-ply laminate envelopes of Fig. 2(a).

The frequency factor envelopes demonstrate good nesting qualities with the new form of the nondimensional frequency factor used. The spacing between each upper- and lower-bound envelope changes only as a result of an expansion in the design space with increasing ply number grouping.

Twelve-ply $\mathbf{A}_{S} \mathbf{B}_{l} \mathbf{D}_{\mathrm{S}}$ laminates have been chosen to investigate the difference between natural frequency factors bounds for the (72) Standard and (1,979) Cross-ply laminates identified in Table 2; this is the lowest ply number grouping in which a range of sub-sequence symmetries are present in both groups. Table 8 (a) provides a list of the stacking sequences forming the upper- and lower-bound fundamental frequency envelopes, $\mathrm{C} 12^{\mathrm{U}}$ and $\mathrm{C} 12^{\mathrm{L}}$, in Fig. 2(a), together with the range of applicable aspect-ratios. Similar listings are provided in Table 8(b) for the frequency envelopes, $\mathrm{S}_{12}{ }^{\mathrm{U}}$ and $\mathrm{S} 12^{\mathrm{L}}$, in Fig. 2(b). The natural frequency is strongly influenced by the bending stiffness across the shortest side length along which the mode shape develops, which explains why the frequency envelopes of the Cross-ply laminates differ so much from those of Standard laminates. The flattening of the Cross-ply envelopes with increasing aspect-ratio is explained by the fact that cross plies are the most effective orientations for maximising the bending stiffness in this case. For small aspect-ratios, $0^{\circ}$ plies dominate the stacking sequence and at high aspect-ratios, $90^{\circ}$ plies dominate; the same trend would be expected in uncoupled laminates. The first $0^{\circ}$ ply constraint, applied to the derivation of the Cross-ply laminates, has influenced the form of the stacking sequences when $90^{\circ}$ plies dominate; the upper-bound stacking sequences for the smallest and highest aspect-ratios, i.e. $\left[\mathrm{O}_{6} / \mathbf{O}_{5}\right]_{\mathrm{T}}$ and $\left[\mathrm{O} / \boldsymbol{\bullet}_{11}\right]_{\mathrm{T}}$, would be identical but with cross plies exchanged, i.e. $\left[\bullet_{6} / \mathrm{O} / \mathbf{G}_{5}\right]_{\mathrm{T}}$ in the latter if this constraint was not applied. This is borne out by the fact that the lower-bound stacking sequence for $a / b=5.0$ does in fact correspond to the upper-bound for $a / b=$ 0.5 . The lower-bound solution for $a / b=1.0$ is anti-symmetric, as expected.

The Standard laminate stacking sequences of Table 8(b) demonstrate that the upper-bound envelope $\mathrm{S} 12^{\mathrm{U}}$ of Fig. 2(b) at $a / b=0.5$ corresponds to the lower-bound envelope $\mathrm{S} 12^{\mathrm{L}}$ at $a / b=5.0$. The bending stiffness, hence frequency is increased around $a / b=1.0$ by placing $\pm 45^{\circ}$ plies outside a central ply block of cross plies; this results in smaller $B_{11}$ and $B_{22}$ terms, hence weaker Extension-Bending coupling. The opposite is seen in stacking sequences of the lower-bound envelope. 
Tests on higher aspect-ratios revealed no changes in the stacking sequences identified in the lists given in Table 8. Additionally, the upper-bound fundamental natural frequency factor result for laminate $[+/ \bigcirc /-/ O /-/ /+/+/ \bigcirc /+/-]_{\mathrm{T}}$, with $\Omega=1.1620$ at aspect-ratio $a / b=5.0$, reduced by $2.80 \%$ at $a / b=10.0$ and by a further $0.73 \%$ at $a / b=20.0$, which justifies curtailment of the range of aspect-ratios presented. To complement the benchmark results presented in Tables 6 and 7, Figs 3 and 4 illustrates the $2^{\text {nd }}$ and $3^{\text {rd }}$ natural frequency factor envelopes, respectively, for Cross-ply and Standard laminates. Similar nesting qualities and trends are observed as in the fundamental frequency envelopes of Fig. 2.

An electronic annex provides additional design curves for the frequency bounds on 12-, 16- and 20- ply laminates, representing Standard and Cross-ply stacking sequence designs with Extension-Bending coupling. Each figure illustrates the first three natural frequency factor envelopes for both Standard and Cross-ply laminate envelopes. These ply number groupings were chosen for direct comparison with a related study [12] on Angle-ply laminate designs with Extension-Twisting (and Shearing-Bending) coupling; the two laminate classes are of course related by an off-axis orientation of $+45^{\circ}$ or $-45^{\circ}$. 


\section{Conclusions.}

New Extension-Bending coupled laminates, with up to 21 plies, have been derived from combinations of standard ply orientations, i.e., $+45,-45,0$ and $90^{\circ}$, and have been shown to exist for all (odd and even) ply number groupings with 9 plies and above. These results serve to dismiss the long-held misconception that this class of laminate is constrained to even ply number groupings of cross-symmetric Cross-ply laminates.

Stacking sequence symmetries have been demonstrated to offer no guarantee of laminate behaviour: nonsymmetric designs have been shown to have fully uncoupled mechanical properties as well as mechanically coupled properties.

Thermal distortions arise in Extension-Bending coupled laminates as a result of either a high temperature curing process or in-service temperature fluctuations, and therefore render this class of laminate functional rather than structural.

Natural frequency factor envelopes have presented, demonstrating the upper- and lower-bounds on the first three natural frequencies for rectangular plates, across a broad range of aspect-ratios. These have revealed an increase in the bounds for Cross-ply laminates when sub-sequence symmetry constraints are removed. Standard laminate configurations have also been shown to produce upper- and lower-bound frequency factor envelopes above and below that of the equivalent fully isotropic laminate.

\section{Acknowledgement.}

The authors gratefully acknowledge the support of the National Natural Science Foundation of China (Grant No. 11472003)

\section{References.}

1. Reddy, J. N., Khdeir, A. A. and Librescu, L. Lévy type solutions for symmetrically laminated rectangular plates using first-order shear deformation theory. Journal of Applied Mechanics, Transactions of the ASME 1987;54:740-742.

2. Khdeir A. A. and Librescu, L. Analysis of symmetric cross-ply laminated elastic plates using higher order theory: Part II — Buckling and Free Vibration. Composite Structures 1988;9:406-436. 
3. Khdeir, A. A. Free vibration and buckling of symmetric cross-ply laminated plates by an exact method. Journal of Sound and Vibration1988;126:447-461.

4. Jones, R. M. Buckling and vibration of rectangular unsymmetrically laminated cross-ply plates. AIAA Journal 1973:1626-1632.

5. Jones, R. M., Morgan, H. S. and Whitney, J. M. Buckling and vibration of antisymmetrically laminated angle-ply rectangular plates. Journal of Applied Mechanics 1973;40:1143-1144.

6. Khdeir, A. A. Free vibration of antisymmetric angle-ply laminated plates including various boundary conditions. Journal of Sound and Vibration 1988;122:377-388.

7. Leissa, A. W. Conditions for laminated plates to remain flat under inplane loading. Composite Structures 1986;6:261-270.

8. Jones, R. M. Mechanics of composite materials. London: Taylor and Francis, 1999.

9. York, C. B. Unified approach to the characterization of coupled composite laminates: Benchmark configurations and special Cases. Journal of Aerospace Engineering, ASCE 2010; 23(4):219-242. 10. Engineering Sciences Data Unit. Stiffnesses of laminated plates. ESDU Item No. 94003, IHS, 1994. 11. York, C. B. Unified approach to the characterization of coupled composite laminates: Hygrothermally curvature-stable configurations. International Journal of Structural Integrity 2011;2(4):406-436. 12. Li, D. and York, C. B. Bounds on the natural frequencies of laminated rectangular plates with extension-twisting (and shearing-bending) coupling. Composite Structures, 2015; Submitted for possible publication.

\section{FIGURE CAPTIONS, FIGURES AND TABLES}

Figure 1 - Laminate cross-section illustrating ply $(k)$ numbering scheme and interface distances $(z)$ from laminate mid-plane in terms of constant ply thickness, $t$.

Figure 2 - Fundamental natural frequency factor bounds for: (a) Cross-ply $\mathbf{A}_{\mathrm{S}} \mathbf{B}_{l} \mathbf{D}_{\mathrm{S}}$ laminates with between ( $n=) 2$ and 21 plies and; (b) Standard $\mathbf{A}_{S} \mathbf{B}_{l} \mathbf{D}_{\mathrm{S}}$ laminates with between ( $\left.n=\right) 9$ and 21 plies). The frequency curve for the equivalent fully isotropic laminate, or FIL, is superimposed for comparison. Numbers following the laminate descriptions C, for Cross-ply laminate, and S, for Standard laminate, 
represent the ply number grouping, $n$. Superscripts L and U represent Lower- and Upper-bound envelopes, respectively.

Figure $3-2^{\text {nd }}$ natural frequency factor bounds for: (a) Cross-ply $\mathbf{A}_{\mathbf{S}} \mathbf{B}_{l} \mathbf{D}_{\mathrm{S}}$ laminates with between $(n=) 2$ and 21 plies and; (b) Standard $\mathbf{A}_{\mathrm{S}} \mathbf{B}_{l} \mathbf{D}_{\mathrm{S}}$ laminates with between $(n=) 9$ and 21 plies). The frequency curve for the equivalent fully isotropic laminate, or FIL, is superimposed for comparison. Numbers following the laminate descriptions C, for Cross-ply laminate, and S, for Standard laminate, represent the ply number grouping, $n$. Superscripts L and U represent Lower- and Upper-bound envelopes, respectively.

Figure $4-3^{\text {rd }}$ natural frequency factor bounds for: (a) Cross-ply $\mathbf{A}_{S} \mathbf{B}_{l} \mathbf{D}_{\mathrm{S}}$ laminates with between $(n=) 2$ and 21 plies and; (b) Standard $\mathbf{A}_{\mathrm{S}} \mathbf{B}_{l} \mathbf{D}_{\mathrm{S}}$ laminates with between $(n=) 9$ and 21 plies). The frequency curve for the equivalent fully isotropic laminate, or FIL, is superimposed for comparison. Numbers following the laminate descriptions C, for Cross-ply laminate, and S, for Standard laminate, represent the ply number grouping, $n$. Superscripts L and U represent Lower- and Upper-bound envelopes, respectively.

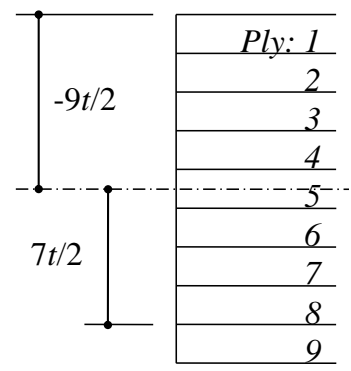

Figure 1 


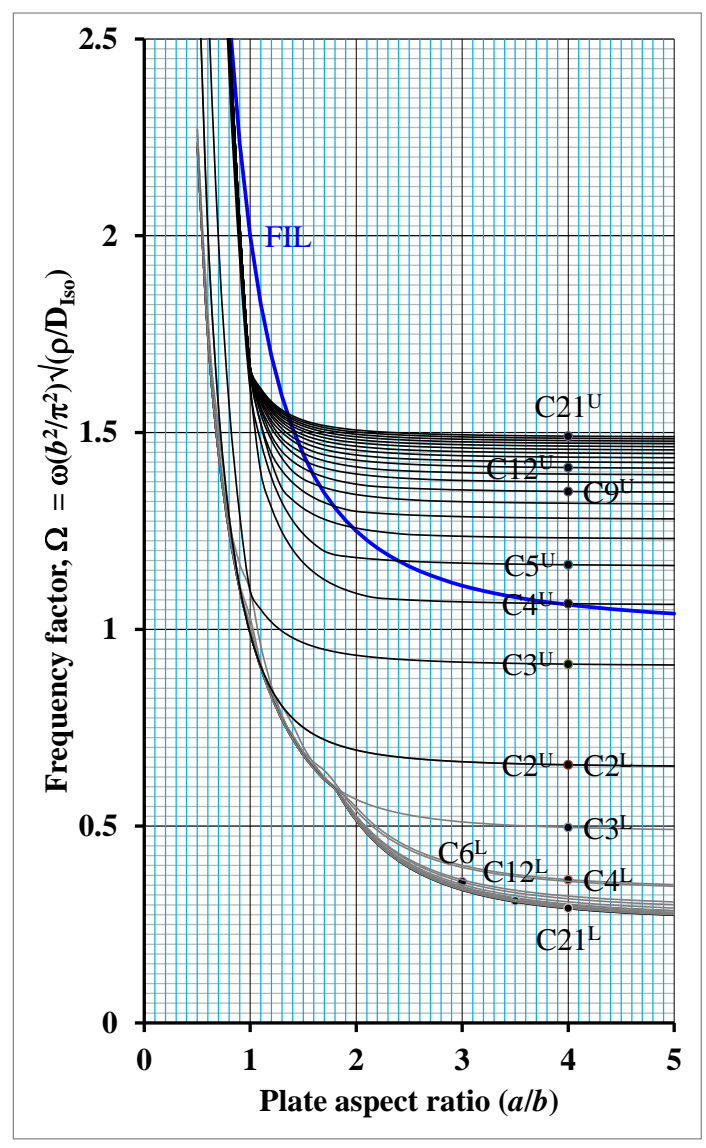

(a)

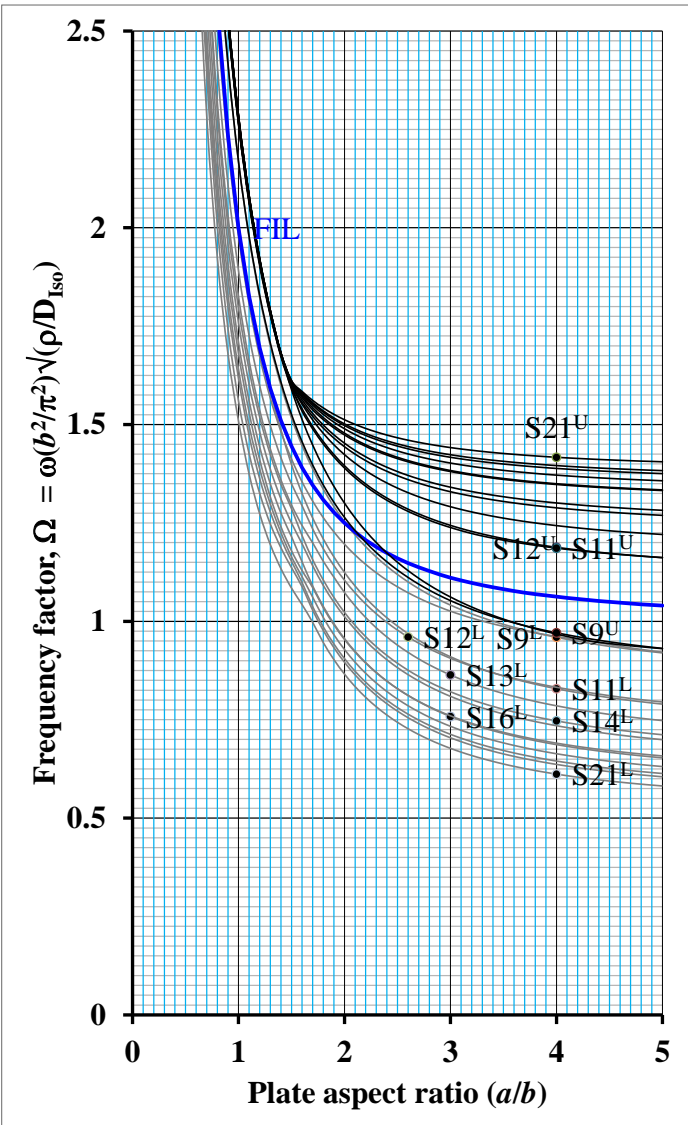

(b)

Figure 2 


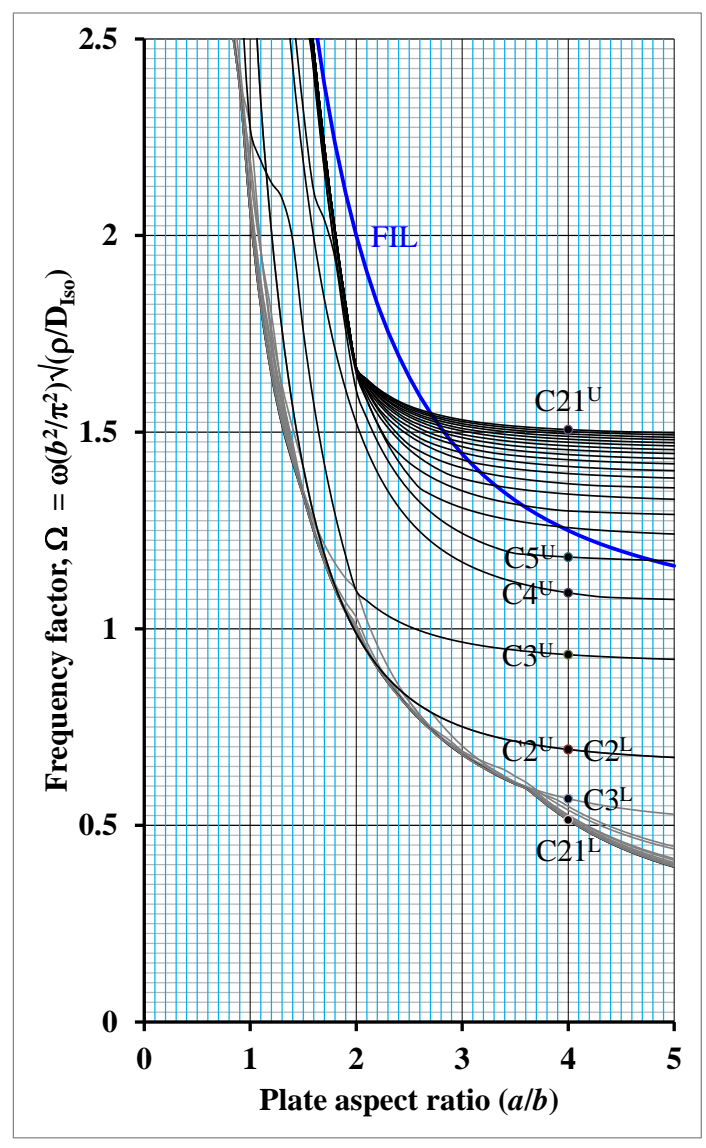

(a)

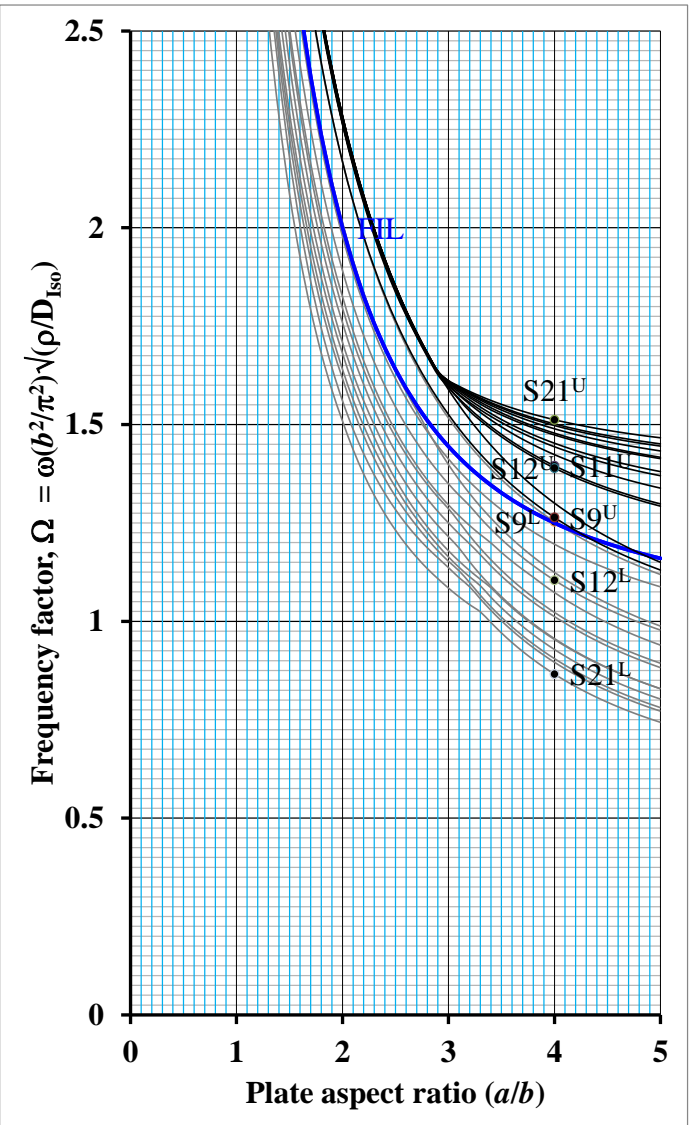

(b)

Figure 3 


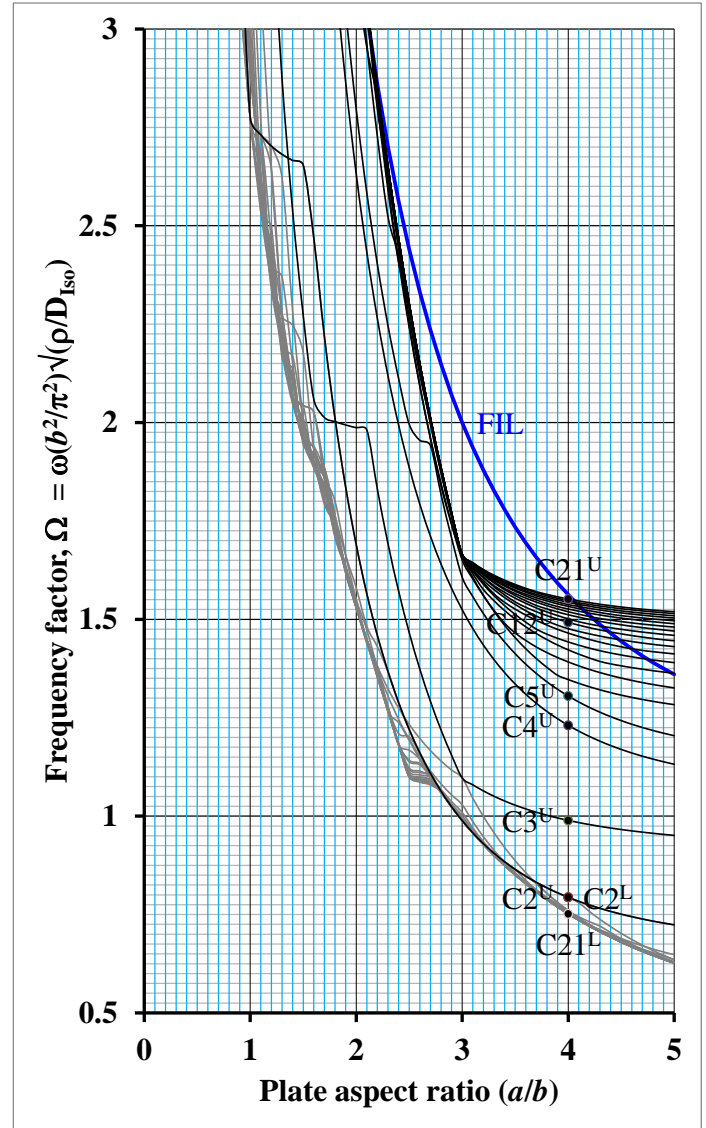

(a)

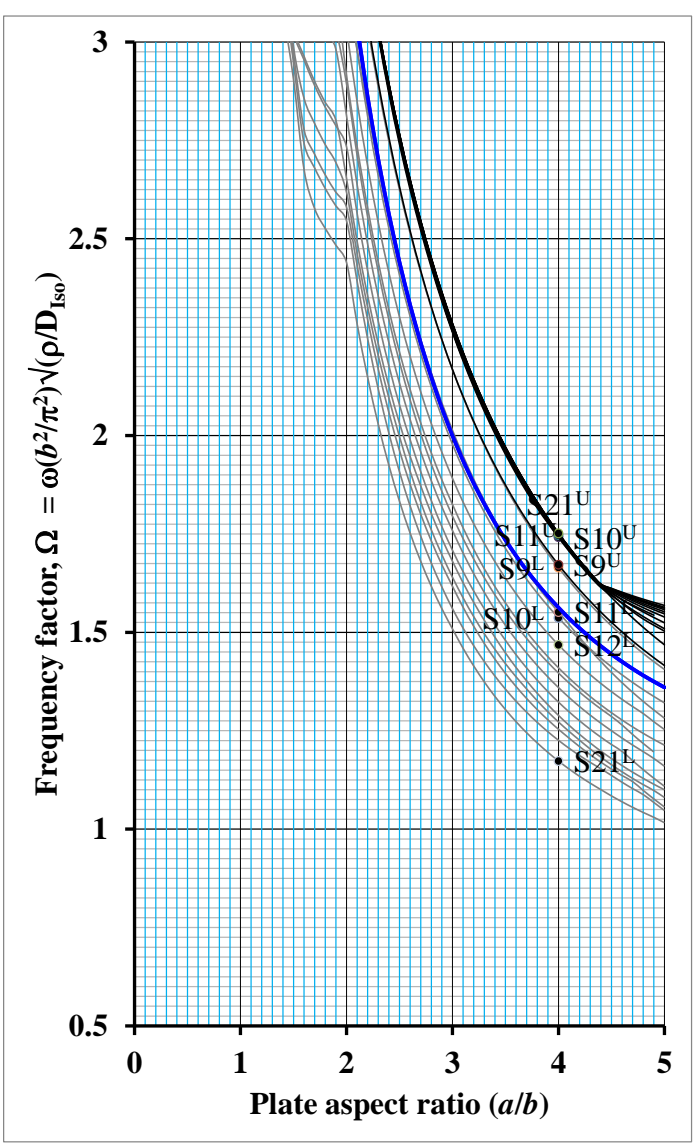

(b)

Figure 4

Table 1 - Calculation procedure for the non-dimensional parameters for an $A_{S} B_{l} D_{S}$ laminate.

\begin{tabular}{|c|c|c|c|c|c|c|c|c|c|c|c|c|c|c|c|c|}
\hline & & \multicolumn{5}{|c|}{ A } & \multicolumn{5}{|c|}{ B } & \multicolumn{5}{|c|}{ D } \\
\hline \multirow{2}{*}{ Ply } & & $\frac{7}{\sqrt[3]{4}}$ & & & ${ }_{\mathrm{A}} \Sigma_{-}$ & & $\widehat{\widetilde{T}}$ & ${ }_{\mathrm{B}} \Sigma_{\mathrm{O}}$ & & ${ }_{\mathrm{B}} \Sigma_{-}$ & ${ }_{\mathrm{B}} \Sigma_{+}$ & $\widetilde{\tilde{m}_{\frac{\pi}{v}}^{\frac{\pi}{y}}}$ & ${ }_{\mathrm{D}} \Sigma_{\mathrm{O}}$ & ${ }_{\mathrm{D}}{ }^{\Sigma} \bullet$ & ${ }_{\mathrm{D}} \Sigma_{-}$ & ${ }_{\mathrm{D}} \Sigma_{+}$ \\
\hline & $\theta$ & $\frac{1}{a}$ & $\underline{\underline{1}}$ & $\underline{\underline{2}}$ & $\underline{\underline{3}}$ & $\underline{\underline{3}}$ & $\overbrace{}^{1}$ & $\underline{\underline{-4}}$ & $\underline{\underline{4}}$ & $\underline{\underline{0}}$ & $\underline{\underline{0}}$ & $\underbrace{1}$ & $\underline{\underline{12.25}}$ & $\underline{12.50}$ & $\underline{78.75}$ & $\underline{\underline{78.75}}$ \\
\hline 1 & + & 1 & & 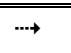 & & 1 & -8 & & $\rightarrow \rightarrow$ & & -8 & 48.25 & & $\rightarrow \rightarrow$ & & 48.25 \\
\hline 2 & - & 1 & & & 1 & & -6 & $\cdots$ & & -6 & & 27.25 & $\rightarrow$ & & 27.25 & \\
\hline 3 & 0 & 1 & $\rightarrow 1$ & & & & -4 & $\rightarrow \quad-4$ & & & & 12.25 & $\rightarrow 12.25$ & & & \\
\hline 4 & - & 1 & & & 1 & & -2 & $\cdots$ & & -2 & & 3.25 & $\rightarrow$ & & 3.25 & \\
\hline 5 & 0 & 1 & $\rightarrow$ & 1 & & & 0 & $\rightarrow$ & 0 & & & 0.25 & $\rightarrow$ & 0.25 & & \\
\hline 6 & + & 1 & & $\cdots$ & & 1 & 2 & & 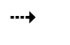 & & 2 & 3.25 & & $\rightarrow$ & & 3.25 \\
\hline 7 & 0 & 1 & $\rightarrow$ & 1 & & & 4 & $\rightarrow$ & 4 & & & 12.25 & $\rightarrow$ & 12.25 & & \\
\hline 8 & + & 1 & & $\cdots$ & & 1 & 6 & & 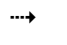 & & 6 & 27.25 & & $\rightarrow$ & & 27.25 \\
\hline 9 & - & 1 & & & 1 & & 8 & $\rightarrow$ & & 8 & & 48.25 & $\cdots$ & & 48.25 & \\
\hline
\end{tabular}


Table 2 - Number of solutions for $\mathbf{A}_{S} \mathbf{B}_{l} \mathbf{D}_{\mathrm{S}}$ laminates with up to $(n=) 21$ layers. Standard laminate configurations represent those with combinations of angle plies $\left( \pm 45^{\circ}\right)$ and cross plies $\left(0\right.$ and/or $\left.90^{\circ}\right)$.

\begin{tabular}{|c|c|c|c|c|c|c|c|c|c|c|c|c|c|c|c|c|c|c|c|c|}
\hline$n$ & 2 & 3 & 4 & 5 & 6 & 7 & 8 & 9 & 10 & 11 & 12 & 13 & 14 & 15 & 16 & 17 & 18 & 19 & 20 & 21 \\
\hline 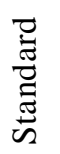 & 1 & 1 & 1 & 1 & 1 & ' & ' & $\nabla$ & 0 & 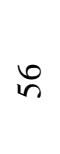 & $\mathbb{N}$ & $\begin{array}{l}\circ \\
n \\
m\end{array}$ & స్ & $\frac{N}{2}$ & 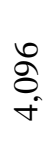 & $\begin{array}{l}\infty \\
\infty \\
0 \\
\text { d }\end{array}$ & $\begin{array}{l}\infty \\
\stackrel{n}{n} \\
m\end{array}$ & \begin{tabular}{l} 
N \\
n \\
\multirow{2}{+}{}
\end{tabular} & 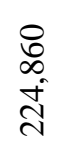 & $\begin{array}{l} \pm \\
\infty \\
0 \\
= \\
=\end{array}$ \\
\hline $\begin{array}{l}\vec{\lambda} \\
\frac{1}{1} \\
0 \\
0 \\
0 \\
0 \\
0\end{array}$ & - & $N$ & 6 & $\mathcal{N}$ & $\stackrel{\infty}{\sim}$ & $\stackrel{+}{n}$ & $\stackrel{\Omega}{=}$ & હે & $\stackrel{\infty}{\infty}$ & $\stackrel{\infty}{a}$ & $\stackrel{a}{\hat{a}}$ & $\begin{array}{l}8 \\
\infty \\
\infty \\
\text { r. }\end{array}$ & $\frac{\infty}{\sigma}$ & 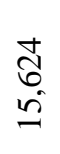 & $\begin{array}{l}\text { Na } \\
\text { o } \\
\text { ñ }\end{array}$ & $\begin{array}{l}\bar{\sigma} \\
\tilde{\sigma}\end{array}$ & $\begin{array}{l}\stackrel{0}{+} \\
\stackrel{1}{\infty} \\
\stackrel{1}{d}\end{array}$ & 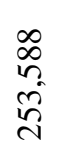 & 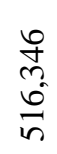 & $\begin{array}{l}\text { No } \\
0 \\
0 \\
0\end{array}$ \\
\hline
\end{tabular}


Table 3 - Abridged stacking sequence listing for $(n=) 12$ layer Standard $\mathbf{A}_{\mathrm{S}} \mathbf{B}_{l} \mathbf{D}_{\mathrm{S}}$ laminates.

\begin{tabular}{|c|c|c|c|c|c|c|c|c|c|c|c|c|c|c|c|c|c|c|c|c|c|c|c|c|}
\hline \multirow{2}{*}{ Ref } & \multirow{2}{*}{\multicolumn{12}{|c|}{ Stacking sequence }} & \multicolumn{11}{|c|}{ Non-dimensional parameters } & \multirow[b]{2}{*}{$\zeta_{n}$} \\
\hline & & & & & & & & & & & & & $n_{+}$ & $n_{-}$ & $n_{0}$ & $n_{0}$ & $\chi_{+}$ & $\chi_{-}$ & $x_{n}$ & $\chi_{0}$ & $\zeta_{+}$ & $\zeta_{-}$ & $\zeta_{0}$ & \\
\hline 1 & + & $\mathrm{O}$ & - & $\mathrm{O}$ & - & - & + & + & O & + & O & - & 8 & 8 & 2 & 2 & 0 & 0 & -28 & 28 & 544 & 544 & 320 & 320 \\
\hline 3 & + & - & $\mathrm{O}$ & $\mathrm{O}$ & - & + & - & + & ○ & ○ & + & - & 8 & 8 & 2 & 2 & 0 & 0 & -24 & 24 & 640 & 640 & 224 & 224 \\
\hline 7 & + & O & - & - & $\mathrm{O}$ & + & - & $\mathrm{O}$ & + & + & 0 & - & 8 & 8 & 3 & 1 & 0 & 0 & -18 & 18 & 592 & 592 & 300 & 244 \\
\hline 8 & + & - & 0 & - & + & 0 & 0 & - & + & 0 & + & - & 8 & 8 & 2 & 2 & 0 & 0 & -16 & 16 & 712 & 712 & 152 & 152 \\
\hline 12 & + & - & 0 & - & + & 0 & 0 & - & + & 0 & + & - & 8 & 8 & 3 & 1 & 0 & 0 & -14 & 14 & 712 & 712 & 156 & 148 \\
\hline 15 & + & - & - & 0 & + & 0 & 0 & + & 0 & - & - & + & 8 & 8 & 2 & 2 & 0 & 0 & -12 & 12 & 784 & 784 & 80 & 80 \\
\hline 21 & + & - & - & 0 & + & 0 & 0 & + & 0 & - & - & + & 8 & 8 & 3 & 1 & 0 & 0 & -10 & 10 & 784 & 784 & 84 & 76 \\
\hline 24 & + & - & - & + & 0 & 0 & 0 & 0 & - & + & + & - & 8 & 8 & 2 & 2 & 0 & 0 & -8 & 8 & 832 & 832 & 32 & 32 \\
\hline 28 & + & - & - & + & 0 & 0 & 0 & 0 & - & + & + & - & 8 & 8 & 3 & 1 & 0 & 0 & -6 & 6 & 832 & 832 & 36 & 28 \\
\hline 30 & + & - & - & + & 0 & 0 & 0 & 0 & - & + & + & - & 8 & 8 & 2 & 2 & 0 & 0 & -4 & 4 & 832 & 832 & 32 & 32 \\
\hline 36 & + & - & - & + & 0 & 0 & 0 & 0 & - & + & + & - & 8 & 8 & 3 & 1 & 0 & 0 & -2 & 2 & 832 & 832 & 60 & 4 \\
\hline
\end{tabular}

Table 4 - Abridged stacking sequence listing for $(n=) 12$ layer Cross-ply $\mathbf{A}_{\mathrm{S}} \mathbf{B}_{l} \mathbf{D}_{\mathrm{S}}$ laminate.

\begin{tabular}{|c|c|c|c|c|c|c|c|c|c|c|c|c|c|c|c|c|c|c|c|c|c|c|c|}
\hline \multirow{2}{*}{ Ref. } & \multirow{2}{*}{\multicolumn{11}{|c|}{ Stacking sequence }} & \multicolumn{11}{|c|}{ Non-dimensional parameters } & \multirow[b]{2}{*}{$\zeta_{\bullet}$} \\
\hline & & & & & & & & & & & & $n_{+}$ & $n_{-}$ & $n_{0}$ & $n_{0}$ & $\chi_{+}$ & $\chi_{-}$ & $\chi_{0}$ & $x_{0}$ & $\zeta_{+}$ & $\zeta_{-}$ & $\zeta_{0}$ & \\
\hline 1 & $\mathrm{O}$ & $\mathrm{O}$ & $\mathrm{O}$ & $\mathrm{O}$ & 0 & $\mathrm{O}$ & 0 & 0 & 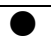 & 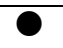 & 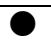 & 0 & 0 & 6 & 6 & 0 & 0 & -72 & 72 & 0 & 0 & 864 & 864 \\
\hline 3 & $\mathrm{O}$ & 0 & $\mathrm{O}$ & $\mathrm{O}$ & 0 & 0 & O & 0 & 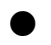 & 0 & 0 & 0 & 0 & 7 & 5 & 0 & 0 & -70 & 70 & 0 & 0 & 868 & 860 \\
\hline 19 & 0 & $\mathrm{O}$ & $\mathrm{O}$ & $\mathrm{O}$ & 0 & 0 & O & O & 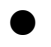 & 0 & 0 & 0 & 0 & 8 & 4 & 0 & 0 & -60 & 60 & 0 & 0 & 944 & 784 \\
\hline 74 & 0 & 0 & 0 & 0 & 0 & 0 & 0 & 0 & 0 & 0 & 0 & 0 & 0 & 7 & 5 & 0 & 0 & -50 & 50 & 0 & 0 & 1228 & 500 \\
\hline 201 & 0 & 0 & 0 & 0 & 0 & 0 & 0 & 0 & 0 & 0 & 0 & 0 & 0 & 8 & 4 & 0 & 0 & -40 & 40 & 0 & 0 & 1304 & 424 \\
\hline 424 & 0 & 0 & 0 & 0 & 0 & 0 & 0 & 0 & 0 & 0 & 0 & 0 & 0 & 9 & 3 & 0 & 0 & -30 & 30 & 0 & 0 & 1476 & 252 \\
\hline 735 & 0 & 0 & 0 & 0 & 0 & 0 & 0 & 0 & 0 & 0 & 0 & 0 & 0 & 10 & 2 & 0 & 0 & -20 & 20 & 0 & 0 & 1552 & 176 \\
\hline 1096 & 0 & 0 & 0 & 0 & 0 & 0 & 0 & 0 & 0 & 0 & 0 & 0 & 0 & 11 & 1 & 0 & 0 & -10 & 10 & 0 & 0 & 1652 & 76 \\
\hline 1170 & 0 & 0 & 0 & 0 & 0 & 0 & 0 & 0 & 0 & 0 & 0 & 0 & 0 & 10 & 2 & 0 & 0 & -8 & 8 & 0 & 0 & 1696 & 32 \\
\hline 1243 & 0 & 0 & 0 & 0 & 0 & 0 & 0 & 0 & 0 & 0 & 0 & 0 & 0 & 11 & 1 & 0 & 0 & -6 & 6 & 0 & 0 & 1700 & 28 \\
\hline 1313 & 0 & 0 & 0 & 0 & 0 & 0 & 0 & 0 & 0 & 0 & 0 & 0 & 0 & 10 & 2 & 0 & 0 & -4 & 4 & 0 & 0 & 1696 & 32 \\
\hline 1379 & 0 & 0 & 0 & 0 & 0 & 0 & 0 & 0 & 0 & 0 & 0 & 0 & 0 & 11 & 1 & 0 & 0 & -2 & 2 & 0 & 0 & 1724 & 4 \\
\hline
\end{tabular}


Table 5 - Fundamental natural frequency factor comparisons, $\Omega^{\prime}$ and $\Omega$, for simply supported rectangular plates, with aspect-ratio (a/b): (a) 1.0; (b) 2.0 and; (c) 3.0, for a $\left[(0 / 90)_{n / 2}\right]_{\mathrm{T}}$ laminate. Ref. [4] results using Eq. (16) are compared with upper- $\left(\Omega^{\mathrm{U}}\right)$ and lower-bound $\left(\Omega^{\mathrm{L}}\right)$ solutions for each ply number grouping, $n$.

(a)

\begin{tabular}{ccccccc}
\hline & & Ref. [4] & MSC/NASTRAN & Ref. [4] & \multicolumn{2}{c}{ Eq. (16) } \\
$a / b$ & $\Omega^{\prime}$ & $\Omega^{\prime}$ & $\Omega$ & $\Omega^{\mathrm{U}}$ & $\Omega^{\mathrm{L}}$ \\
\hline \multirow{2}{*}{1} & 2 & 0.86476 & 0.8646 & 0.9886 & 0.9886 & 0.9886 \\
& 4 & 1.3335 & 1.3332 & 1.5244 & 1.6216 & 0.9886 \\
& 6 & 1.4033 & 1.4029 & 1.6041 & 1.6585 & 0.9886 \\
\hline
\end{tabular}

(b)

\begin{tabular}{ccccccc}
\hline & & Ref. [4] & MSC/NASTRAN & Ref. [4] & \multicolumn{2}{c}{ Eq. (16) } \\
$a / b$ & $\Omega^{\prime}$ & $\Omega^{\prime}$ & $\Omega$ & $\Omega^{\mathrm{U}}$ & $\Omega^{\mathrm{L}}$ \\
\hline \multirow{2}{*}{2} & 2 & 0.60637 & 0.6063 & 0.6932 & 0.6932 & 0.6932 \\
& 4 & 0.95479 & 0.9547 & 1.0915 & 1.0915 & 0.5482 \\
& 6 & 1.0062 & 1.0060 & 1.1502 & 1.2573 & 0.5252 \\
\hline
\end{tabular}

(c)

\begin{tabular}{ccccccc}
\hline & & Ref. [4] & MSC/NASTRAN & Ref. [4] & \multicolumn{2}{c}{ Eq. (16) } \\
$a / b$ & $\Omega^{\prime}$ & $\Omega^{\prime}$ & $\Omega$ & $\Omega^{\mathrm{U}}$ & $\Omega^{\mathrm{L}}$ \\
\hline \multirow{3}{*}{3} & 2 & 0.5809 & 0.5805 & 0.6636 & 0.6636 & 0.6636 \\
& 4 & 0.92393 & 0.9238 & 1.0562 & 1.0697 & 0.4002 \\
& 6 & 0.97434 & 0.9742 & 1.1138 & 1.2365 & 0.3584 \\
\hline
\end{tabular}

Table $6-2^{\text {nd }}$ natural frequency factor comparisons, $\Omega^{\prime}$ and $\Omega$, for simply supported rectangular plates, with aspect-ratio (a/b): (a) 1.0; (b) 2.0 and; (c) 3.0, for a $\left[(0 / 90)_{n / 2}\right]_{\mathrm{T}}$ laminate. Ref. [4] results using Eq. (16) are compared with upper- $\left(\Omega^{\mathrm{U}}\right)$ and lower-bound $\left(\Omega^{\mathrm{L}}\right)$ solutions for each ply number grouping, $n$.

(a)

\begin{tabular}{|c|c|c|c|c|c|c|}
\hline \multirow[b]{2}{*}{$a / b$} & & \multirow{2}{*}{$\begin{array}{c}\text { Ref. [4] } \\
\Omega^{\prime}\end{array}$} & \multirow{2}{*}{$\begin{array}{c}\text { MSC/NASTRAN }^{\circledR} \\
\Omega^{\prime}\end{array}$} & \multirow{2}{*}{$\begin{array}{c}\text { Ref. [4] } \\
\Omega\end{array}$} & \multicolumn{2}{|c|}{ Eq. (16) } \\
\hline & & & & & $\Omega^{\mathrm{U}}$ & $\Omega^{\mathrm{L}}$ \\
\hline \multirow{3}{*}{1} & 2 & 2.4255 & 2.4248 & 2.7727 & 2.7727 & 2.7727 \\
\hline & 4 & 3.8192 & 3.8175 & 4.3659 & 4.3659 & 2.1927 \\
\hline & 6 & 4.0247 & 4.0229 & 4.6008 & 4.7608 & 2.1009 \\
\hline \multicolumn{7}{|c|}{ (b) } \\
\hline \multirow[b]{2}{*}{$a / b$} & & Ref. [4] & MSC/NASTRAN $^{\circledR}$ & Ref. [4] & \multicolumn{2}{|c|}{ Eq. (16) } \\
\hline & & $\Omega^{\prime}$ & $\Omega^{\prime}$ & $\Omega$ & $\Omega^{\mathrm{U}}$ & $\Omega^{\mathrm{L}}$ \\
\hline \multirow{3}{*}{2} & 2 & 0.8648 & 0.8646 & 0.9886 & 0.9886 & 0.9886 \\
\hline & 4 & 1.3335 & 1.3332 & 1.5244 & 1.5244 & 0.9886 \\
\hline & 6 & 1.4033 & 1.4029 & 1.6041 & 1.6585 & 0.9886 \\
\hline \multicolumn{7}{|c|}{ (c) } \\
\hline \multirow[b]{2}{*}{$a / b$} & & Ref. [4] & MSC/NASTRAN $^{\circledR}$ & Ref. [4] & \multicolumn{2}{|c|}{ Eq. (16) } \\
\hline & & $\Omega^{\prime}$ & $\Omega^{\prime}$ & $\Omega$ & $\Omega^{\mathrm{U}}$ & $\Omega^{\mathrm{L}}$ \\
\hline \multirow{3}{*}{3} & 2 & 0.6569 & 0.6568 & 0.7509 & 0.7509 & 0.7509 \\
\hline & 4 & 1.0230 & 1.0229 & 1.1695 & 1.1695 & 0.7022 \\
\hline & 6 & 1.0773 & 1.0771 & 1.2315 & 1.3074 & 0.6799 \\
\hline
\end{tabular}


Table $7-3^{\text {rd }}$ natural frequency factor comparisons, $\Omega^{\prime}$ and $\Omega$, for simply supported rectangular plates, with aspect-ratio (a/b): (a) 1.0; (b) 2.0 and; (c) 3.0, for a $\left[(0 / 90)_{n / 2}\right]_{\mathrm{T}}$ laminate. Ref. [4] results using Eq. (16) are compared with upper- $\left(\Omega^{\mathrm{U}}\right)$ and lower-bound $\left(\Omega^{\mathrm{L}}\right)$ solutions for each ply number grouping, $n$.

(a)

\begin{tabular}{ccccccc}
\hline & & Ref. [4] & MSC/NASTRAN & Ref. [4] & \multicolumn{2}{c}{ Eq. (16) } \\
$a / b$ & $\Omega^{\prime}$ & $\Omega^{\prime}$ & $\Omega$ & $\Omega^{\mathrm{U}}$ & $\Omega^{\mathrm{L}}$ \\
\hline \multirow{3}{*}{1} & 2 & 2.4255 & 2.4248 & 2.7727 & 2.7727 & 2.7727 \\
& 4 & 3.8192 & 3.8175 & 4.3659 & 4.3659 & 2.7727 \\
& 6 & 4.0247 & 4.0229 & 4.6008 & 5.7964 & 2.7727 \\
\hline
\end{tabular}

(b)

\begin{tabular}{ccccccc}
\hline & & Ref. [4] & MSC/NASTRAN & Ref. [4] & \multicolumn{2}{c}{ Eq. (16) } \\
$a / b$ & $\Omega^{\prime}$ & $\Omega^{\prime}$ & $\Omega$ & $\Omega^{\mathrm{U}}$ & $\Omega^{\mathrm{L}}$ \\
\hline \multirow{2}{*}{2} & 2 & 1.4780 & 1.4777 & 1.6896 & 1.6896 & 1.6896 \\
& 4 & 2.3019 & 2.3011 & 2.6314 & 2.6314 & 1.5800 \\
& 6 & 2.4239 & 2.4231 & 2.7709 & 3.2339 & 1.5299 \\
\hline
\end{tabular}

(c)

\begin{tabular}{ccccccc}
\hline & & Ref. [4] & MSC/NASTRAN & Ref. [4] & \multicolumn{2}{c}{ Eq. (16) } \\
$a / b$ & $\Omega^{\prime}$ & $\Omega^{\prime}$ & $\Omega$ & $\Omega^{\mathrm{U}}$ & $\Omega^{\mathrm{L}}$ \\
\hline \multirow{3}{*}{3} & 2 & 0.8648 & 0.8646 & 0.9886 & 0.9886 & 0.9886 \\
& 4 & 1.3335 & 1.3332 & 1.5244 & 1.5244 & 0.9886 \\
& 6 & 1.4033 & 1.4029 & 1.6041 & 1.6585 & 0.9886 \\
\hline
\end{tabular}

Table 8 - Stacking sequences corresponding to upper- and lower-bound curves of the fundamental frequency factors of Fig. 1 for: (a) Cross-ply and; (b) Standard $\mathbf{A}_{\mathrm{S}} \mathbf{B}_{l} \mathbf{D}_{\mathrm{S}}$ laminates with $n=12$.

(a)

\begin{tabular}{|c|c|c|c|}
\hline$a / b$ & Upper-bound & $a / b$ & Lower-bound \\
\hline $0.5-0.9$ & {$[O / O / O / O / O / O / O / O / O / O / O / O]_{\mathrm{T}}$} & 0.5 & {$[\mathrm{O} / \mathrm{O} / \mathrm{O} / \mathrm{C}$} \\
\hline 1.0 & '/০/O/O/O/O/O/O/O $]_{\mathrm{T}}$ & $0.6-0.7$ & {$[\mathrm{O} / \mathrm{O} / \mathrm{O} / \mathrm{O} /$} \\
\hline 1.1 & / /O/O/O/O/O/O $]_{\mathrm{T}}$ & $0.8-0.9$ & {$[\mathrm{O} / \mathrm{O} / \mathrm{O} / \mathrm{O} / \mathrm{C}$} \\
\hline $1.2-1.6$ & {$[\mathrm{O} / \mathrm{C}$} & $1.0-1.1$ & {$[O / O / O / O / O / O /$} \\
\hline $1.7-2.9$ & {$[0$} & $1.2-1.3$ & {$[\mathrm{O} / \mathrm{O} / \mathrm{O} / \mathrm{O} / \mathrm{O} / \mathrm{O} / \mathrm{O} /$} \\
\hline $3.0-5.0$ & {$[\mathrm{O} / \mathrm{C}$} & $1.4-1.7$ & {$[\mathrm{O} / \mathrm{O} / \mathrm{O} / \mathrm{O} / \mathrm{O} / \mathrm{O} / \mathrm{C}$} \\
\hline & & 1.8 & {$[\mathrm{O} / \mathrm{O} / \mathrm{O} / \mathrm{O} / \mathrm{O} / \mathrm{O} / \mathrm{O} /$} \\
\hline & & $1.9-5.0$ & {$[0 / O / O / O / O / O / O / O / O$} \\
\hline
\end{tabular}

(b)

\begin{tabular}{|c|c|c|c|}
\hline$a / b$ & Upper-bound & $a / b$ & Lower-bound \\
\hline $0.5-0.6$ & {$[+/ \mathrm{O} /-/-/ \mathrm{O} /+/-/ \mathrm{O} /+/+/ \mathrm{O} /-]_{\mathrm{T}}$} & $0.5-0.6$ & {$[+/ \mathbf{O} /-/ \mathrm{O} /-/-/+/+/ \mathbf{O} /+/ \mathbf{O} /-]_{\mathrm{T}}$} \\
\hline $0.7-0.9$ & {$[+/-/-/+/ 0 / 0 / 0 / 0 /-/+/+/-]_{\mathrm{T}}$} & $0.7-1.5$ & {$[+/ O /-/ O /-/-/+/+/ O /+/ O /-]_{\mathrm{T}}$} \\
\hline $1.0-1.4$ & {$[+/-/-/+/ \mathbf{O} / \mathbf{O} / \mathbf{O} /-/+/+/-]_{\mathrm{T}}$} & $1.6-4.2$ & {$[+/ \mathrm{O} /-/ \mathrm{O} /-/-/+/+/ \mathrm{O} /+/ \mathrm{O} /-]_{\mathrm{T}}$} \\
\hline 1.5 & {$[+/-/ O /-/+/ O /$} & $4.3-5.0$ & {$[+/ O /-/-/ O /+/-/ O /+/+/ O /-]_{\mathrm{T}}$} \\
\hline $1.6-5.0$ & {$[+/ \mathbf{O} / / \mathbf{O} /-/-/+/+/ \mathbf{O} /+/ \mathbf{O} /-]_{\mathrm{T}}$} & & \\
\hline
\end{tabular}




\section{Electronic Annex}

This section presents a proof for the non-dimensional constraints used in the development of the Extension-Bending coupled $\left(\mathrm{A}_{S} \mathrm{~B}_{l} \mathrm{D}_{\mathrm{S}}\right)$ laminates presented in the main body of the article, together with additional design curves for the frequency bounds on 12-, 16- and 20-ply laminates, representing Standard and Cross-ply stacking sequence designs with Extension-Bending coupling. These ply number groupings were chosen for direct comparison with a related study ${ }^{3}$, in which Hygro-Thermally Curvature Stable (HTCS) or warp-free laminates are compared against both Standard and Angle-ply laminates with Extension-Twisting (and Shearing-Bending) coupling. Warp-free laminates can be manufactured using a high temperature curing system without introducing unwanted thermal distortions on cooling; they are also free from such distortions in service. The Standard and Angle-ply laminates presented, as with all the designs presented in this article, require either special curved tooling or cold cure resin systems to achieve the desired shape after manufacture; they also remain subject to thermal distortions in service.

\footnotetext{
${ }^{3} \mathrm{Li}$, D. and York, C. B. Bounds on the natural frequencies of laminated rectangular plates with extension-twisting (and shearing-bending) coupling. Composite Structures, 2015; Submitted for possible publication.
} 


\section{Proof for non-dimensional design constraints}

The non-dimensional parameter constraints given in Eq. (12) of the main body of the article were derived for laminates containing $0^{\circ}$ and $90^{\circ}$ cross plies and angle plies with arbitrary orientations $\pm \theta^{\circ}$.

Elements of the stiffness matrices are related to lamination parameters and laminate invariants, originally conceived by Tsai and $\mathrm{Hahn}^{4}$, by:

$$
\begin{aligned}
& \mathrm{A}_{11}=\left\{U_{1}+\xi_{1} U_{2}+\xi_{2} U_{3}\right\} \times H \\
& \mathrm{~A}_{12}=\mathrm{A}_{21}=\left\{-\xi_{2} U_{3}+U_{4}\right\} \times H \\
& \mathrm{~A}_{16}=\mathrm{A}_{61}=\left\{\xi_{3} U_{2} / 2+\xi_{4} U_{3}\right\} \times H \\
& \mathrm{~A}_{22}=\left\{U_{1}-\xi_{1} U_{2}+\xi_{2} U_{3}\right\} \times H \\
& \mathrm{~A}_{26}=\mathrm{A}_{62}=\left\{\xi_{3} U_{2} / 2-\xi_{4} U_{3}\right\} \times H \\
& \mathrm{~A}_{66}=\left\{-\xi_{2} U_{3}+U_{5}\right\} \times H
\end{aligned}
$$

$\mathrm{B}_{11}=\left\{\xi_{5} U_{2}+\xi_{6} U_{3}\right\} \times H^{2} / 4$

$\mathrm{B}_{12}=\mathrm{B}_{21}=\left\{-\xi_{6} U_{3}\right\} \times H^{2} / 4$

$\mathrm{B}_{16}=\mathrm{B}_{61}=\left\{\xi_{7} U_{2} / 2+\xi_{8} U_{3}\right\} \times H^{2} / 4$

$\mathrm{B}_{22}=\left\{-\xi_{5} U_{2}+\xi_{6} U_{3}\right\} \times H^{2} / 4$

$\mathrm{B}_{26}=\mathrm{B}_{62}=\left\{\xi_{7} U_{2} / 2-\xi_{8} U_{3}\right\} \times H^{2} / 4$

$\mathrm{B}_{66}=\left\{-\xi_{6} U_{3}\right\} \times H^{2} / 4$

and

$\mathrm{D}_{11}=\left\{U_{1}+\xi_{9} U_{2}+\xi_{10} U_{3}\right\} \times H^{3} / 12$

$\mathrm{D}_{12}=\mathrm{D}_{21}=\left\{U_{4}-\xi_{10} U_{3}\right\} \times H^{3} / 12$

$\mathrm{D}_{16}=\mathrm{D}_{61}=\left\{\xi_{11} U_{2} / 2+\xi_{12} U_{3}\right\} \times H^{3} / 12$

$\mathrm{D}_{22}=\left\{U_{1}-\xi_{9} U_{2}+\xi_{10} U_{3}\right\} \times H^{3} / 12$

$\mathrm{D}_{26}=\mathrm{D}_{62}=\left\{\xi_{11} U_{2} / 2-\xi_{12} U_{3}\right\} \times H^{3} / 12$

$\mathrm{D}_{66}=\left\{-\xi_{10} U_{3}+U_{5}\right\} \times H^{3} / 12$

${ }^{4}$ Tsai, S.W., Hahn, H.T. Introduction to composite materials. Technomic Publishing Co. Inc., Lancaster, 1980. 
where the $U_{\mathrm{i}}$ are calculated from the reduced stiffness terms, $\mathrm{Q}_{\mathrm{ij}}$, of Eq. (11) in the main body of the article:

$U_{1}=\left\{3 \mathrm{Q}_{11}+3 \mathrm{Q}_{22}+2 \mathrm{Q}_{12}+4 \mathrm{Q}_{66}\right\} / 8$

$U_{2}=\left\{\mathrm{Q}_{11}-\mathrm{Q}_{22}\right\} / 2$

$U_{3}=\left\{\mathrm{Q}_{11}+\mathrm{Q}_{22}-2 \mathrm{Q}_{12}-4 \mathrm{Q}_{66}\right\} / 8$

$U_{4}=\left\{\mathrm{Q}_{11}+\mathrm{Q}_{22}+6 \mathrm{Q}_{12}-4 \mathrm{Q}_{66}\right\} / 8$

$U_{5}=\left\{\mathrm{Q}_{11}+\mathrm{Q}_{22}-2 \mathrm{Q}_{12}+4 \mathrm{Q}_{66}\right\} / 8$

The ply orientation dependent lamination parameters are related to the non-dimensional parameters developed in Table 1 by the following expressions:

$\xi_{1}=\xi_{1}{ }^{\mathrm{A}}=\left\{n_{+} \cos \left(2 \theta_{+}\right)+n_{-} \cos \left(2 \theta_{-}\right)+n_{\circ} \cos \left(2 \theta_{\odot}\right)+n_{\bullet} \cos \left(2 \theta_{\bullet}\right)\right\} / n$
$\xi_{2}=\xi_{2}{ }^{\mathrm{A}}=\left\{n_{+} \cos \left(4 \theta_{+}\right)+n_{-} \cos \left(4 \theta_{-}\right)+n_{\odot} \cos \left(4 \theta_{\odot}\right)+n_{\bullet} \cos \left(4 \theta_{\bullet}\right)\right\} / n$
$\xi_{3}=\xi_{3}{ }^{\mathrm{A}}=\left\{n_{+} \sin \left(2 \theta_{+}\right)+n_{-} \sin \left(2 \theta_{-}\right)+n_{\odot} \sin \left(2 \theta_{\odot}\right)+n_{\bullet} \sin \left(2 \theta_{\bullet}\right)\right\} / n$
$\xi_{4}=\xi_{4}{ }^{\mathrm{A}}=\left\{n_{+} \sin \left(4 \theta_{+}\right)+n_{-} \sin \left(4 \theta_{-}\right)+n_{\odot} \sin \left(4 \theta_{\odot}\right)+n_{\bullet} \sin \left(4 \theta_{\bullet}\right)\right\} / n$

$\xi_{5}=\xi_{1}{ }^{\mathrm{B}}=\left\{\chi_{+} \cos \left(2 \theta_{+}\right)+\chi_{-} \cos \left(2 \theta_{-}\right)+\chi_{\circ} \cos \left(2 \theta_{\odot}\right)+\chi_{\bullet} \cos \left(2 \theta_{\bullet}\right)\right\} / n^{2}$

$\xi_{6}=\xi_{2}{ }^{\mathrm{B}}=\left\{\chi_{+} \cos \left(4 \theta_{+}\right)+\chi_{-} \cos \left(4 \theta_{-}\right)+\chi_{\circ} \cos \left(4 \theta_{0}\right)+\chi_{\bullet} \cos \left(4 \theta_{\bullet}\right)\right\} / n^{2}$

$\xi_{7}=\xi_{3}{ }^{\mathrm{B}}=\left\{\chi_{+} \sin \left(2 \theta_{+}\right)+\chi_{-} \sin \left(2 \theta_{-}\right)+\chi_{0} \sin \left(2 \theta_{0}\right)+\chi_{\bullet} \sin \left(2 \theta_{\bullet}\right)\right\} / n^{2}$

$\xi_{8}=\xi_{4}{ }^{\mathrm{B}}=\left\{\chi_{+} \sin \left(4 \theta_{+}\right)+\chi_{-} \sin \left(4 \theta_{-}\right)+\chi_{\circ} \sin \left(4 \theta_{0}\right)+\chi_{\bullet} \sin \left(4 \theta_{\bullet}\right)\right\} / n^{2}$

$\xi_{9}=\xi_{1}{ }^{\mathrm{D}}=\left\{\zeta_{+} \cos \left(2 \theta_{+}\right)+\zeta_{-} \cos \left(2 \theta_{-}\right)+\zeta_{\mathrm{O}} \cos \left(2 \theta_{\odot}\right)+\zeta_{\bullet} \cos \left(2 \theta_{\bullet}\right)\right\} / n^{3}$

$\xi_{10}=\xi_{2}^{\mathrm{D}}=\left\{\zeta_{+} \cos \left(4 \theta_{+}\right)+\zeta_{-} \cos \left(4 \theta_{-}\right)+\zeta_{\mathrm{O}} \cos \left(4 \theta_{\odot}\right)+\zeta_{\bullet} \cos \left(4 \theta_{\bullet}\right)\right\} / n^{3}$

$\xi_{11}=\xi_{3}{ }^{\mathrm{D}}=\left\{\zeta_{+} \sin \left(2 \theta_{+}\right)+\zeta_{-} \sin \left(2 \theta_{-}\right)+\zeta_{\circ} \sin \left(2 \theta_{0}\right)+\zeta_{\bullet} \sin \left(2 \theta_{\bullet}\right)\right\} / n^{3}$

$\xi_{12}=\xi_{4}{ }^{\mathrm{D}}=\left\{\zeta_{+} \sin \left(4 \theta_{+}\right)+\zeta_{-} \sin \left(4 \theta_{-}\right)+\zeta_{\mathrm{O}} \sin \left(4 \theta_{0}\right)+\zeta_{\bullet} \sin \left(4 \theta_{\bullet}\right)\right\} / n^{3}$

For $A_{S} B_{l} D_{S}$ laminate, the elements of the stiffness matrices should satisfy the following constraints:
$\mathrm{A}_{16}=\mathrm{A}_{26}=0$
$\mathrm{B}_{16}=\mathrm{B}_{26}=0$
$\mathrm{D}_{16}=\mathrm{D}_{26}=0$
$\mathrm{B}_{12}=\mathrm{B}_{66}=0$
$\mathrm{B}_{11} \neq 0$
$\mathrm{B}_{22} \neq 0$

Inserting Equations (A1)-(A3) into Equation (A8) gives: 


$$
\begin{array}{lc}
\mathrm{A}_{16}=\mathrm{A}_{26}=0 \rightarrow \xi_{3}=\xi_{4}=0 & \mathrm{~B}_{16}=\mathrm{B}_{26}=0 \rightarrow \xi_{7}=\xi_{8}=0 \\
\mathrm{D}_{16}=\mathrm{D}_{26}=0 \rightarrow \xi_{11}=\xi_{12}=0 & \mathrm{~B}_{12}=\mathrm{B}_{66}=0 \rightarrow \xi_{6}=0 \\
\mathrm{~B}_{11} \neq 0 \rightarrow \xi_{5} \neq 0 & \mathrm{~B}_{22} \neq 0 \rightarrow \xi_{5} \neq 0
\end{array}
$$

Therefore the lamination parameters for $A_{S} B_{l} D_{S}$ laminates should satisfy the following constraints:

$\xi_{3}=\xi_{4}=0$

$\xi_{6}=\xi_{7}=\xi_{8}=0$

$\xi_{11}=\xi_{12}=0$

Applying the lamination parameter constraints of Eq. (A10) to lamination parameters of Eqs (A5) - (A7), for laminates containing $0^{\circ}$ and $90^{\circ}$ cross plies and angle plies with arbitrary orientations $\pm \theta^{\circ}$, gives:

$$
\begin{aligned}
& \xi_{3}=\left\{n_{+} \sin \left(2 \theta_{+}\right)+n_{-} \sin \left(2 \theta_{-}\right)+n_{0} \sin (2 \times 0)+n_{90^{\circ}} \sin (2 \times 90)\right\} / n \\
& \xi_{3}=\left\{n_{+} \sin \left(2 \theta_{+}\right)+n_{-} \sin \left(2 \theta_{-}\right)\right\} / n=0 \quad \rightarrow n_{+}=n_{-} \\
& \xi_{4}=\left\{n_{+} \sin \left(4 \theta_{+}\right)+n_{-} \sin \left(4 \theta_{-}\right)+n_{0} \sin (4 \times 0)+n_{90^{\circ}} \sin (4 \times 90)\right\} / n \\
& \xi_{4}=\left\{n_{+} \sin \left(4 \theta_{+}\right)+n_{-} \sin \left(4 \theta_{-}\right)\right\} / n=0 \quad \rightarrow n_{+}=n_{-} \\
& \xi_{5}=\left\{\chi_{+} \cos \left(2 \theta_{+}\right)+\chi_{-} \cos \left(2 \theta_{-}\right)+\chi_{0} \cos (2 \times 0)+\chi_{90} \cos (2 \times 90)\right\} / n^{2} \\
& \left\{\left(\chi_{+}+\chi_{-}\right) \cos \left(2 \theta_{+}\right)+\chi_{0}-\chi_{90}\right\} / n^{2} \neq 0 \quad \rightarrow\left(\chi_{+}+\chi_{-}\right) \cos \left(2 \theta_{+}\right)+\chi_{0}-\chi_{90} \neq 0 \\
& \xi_{6}=\left\{\chi_{+} \cos \left(4 \theta_{+}\right)+\chi_{-} \cos \left(4 \theta_{-}\right)+\chi_{0} \cos (4 \times 0)+\chi_{90} \cos (4 \times 90)\right\} / n^{2} \\
& \left\{\left(\chi_{+}+\chi_{-}\right) \cos \left(4 \theta_{+}\right)+\chi_{0}+\chi_{90}\right\} / n^{2}=0 \quad \rightarrow\left(\chi_{+}+\chi_{-}\right) \cos \left(4 \theta_{+}\right)+\chi_{0}+\chi_{90}=0 \\
& \xi_{7}=\left\{\chi_{+} \sin \left(2 \theta_{+}\right)+\chi_{-} \sin \left(2 \theta_{-}\right)+\chi_{0} \sin (2 \times 0)+\chi_{90} \sin (2 \times 90)\right\} / n^{2} \\
& \left(\chi_{+}+\chi_{-}\right) \sin \left(2 \theta_{-}\right) / n^{2} \neq 0 \quad \rightarrow \chi_{+}=\chi_{-} \\
& \xi_{8}=\left\{\chi_{+} \sin \left(4 \theta_{+}\right)+\chi_{-} \sin \left(4 \theta_{-}\right)+\chi_{0} \sin (4 \times 0)+\chi_{90} \sin (4 \times 90)\right\} / n^{2} \\
& \left(\chi_{+}+\chi_{-}\right) \sin \left(4 \theta_{-}\right) / n^{2} \neq 0 \quad \rightarrow \chi_{+}=\chi_{-} \\
& \xi_{11}=\left\{\zeta_{+} \sin \left(2 \theta_{+}\right)+\zeta_{-} \sin \left(2 \theta_{-}\right)+\zeta_{0} \sin (2 \times 0)+\zeta_{90^{\circ}} \sin (2 \times 90)\right\} / n \\
& \xi_{11}=\left(\zeta_{+}-\zeta_{-}\right) \sin \left(2 \theta_{+}\right) / n^{3}=0 \quad \rightarrow \zeta_{+}=\zeta_{-} \\
& \xi_{12}=\left\{\zeta_{+} \sin \left(4 \theta_{+}\right)+\zeta_{-} \sin \left(4 \theta_{-}\right)+\zeta_{0} \sin (4 \times 0)+\zeta_{90^{\circ}} \sin (4 \times 90)\right\} / n^{3} \\
& \xi_{12}=\left(\zeta_{+}-\zeta_{-}\right) \sin \left(4 \theta_{+}\right) / n^{3}=0 \quad \rightarrow \zeta_{+}=\zeta_{-}
\end{aligned}
$$


Therefore, the $\mathrm{A}_{S} \mathrm{~B}_{l} \mathrm{D}_{S}$ laminate should satisfy the following non-dimensional parameter constraints when angle-plies (+/-) can be assigned any arbitrary orientation, $0<\theta<90^{\circ}$, and the cross-plies $(\mathrm{O} / \mathbf{O}$, representing $0^{\circ} / 90^{\circ}$ ) can be interchanged:

$n_{+}=n_{-}$

$\left(\chi_{+}+\chi_{-}\right) \cos (2 \theta)+\chi_{\circ}-\chi_{\bullet} \neq 0$

$\left(\chi_{+}+\chi_{-}\right) \cos (4 \theta)+\chi_{0}+\chi_{\bullet}=0$

$\chi_{+}=\chi_{-}$

$\zeta_{+}=\zeta_{-}$

or

$n_{+}=n_{-}$

$\chi_{+}=\chi_{-}=0$

$\chi_{0}=-\chi_{\bullet} \neq 0$

$\zeta_{+}=\zeta_{-}$ 
Design curves for the frequency bounds.

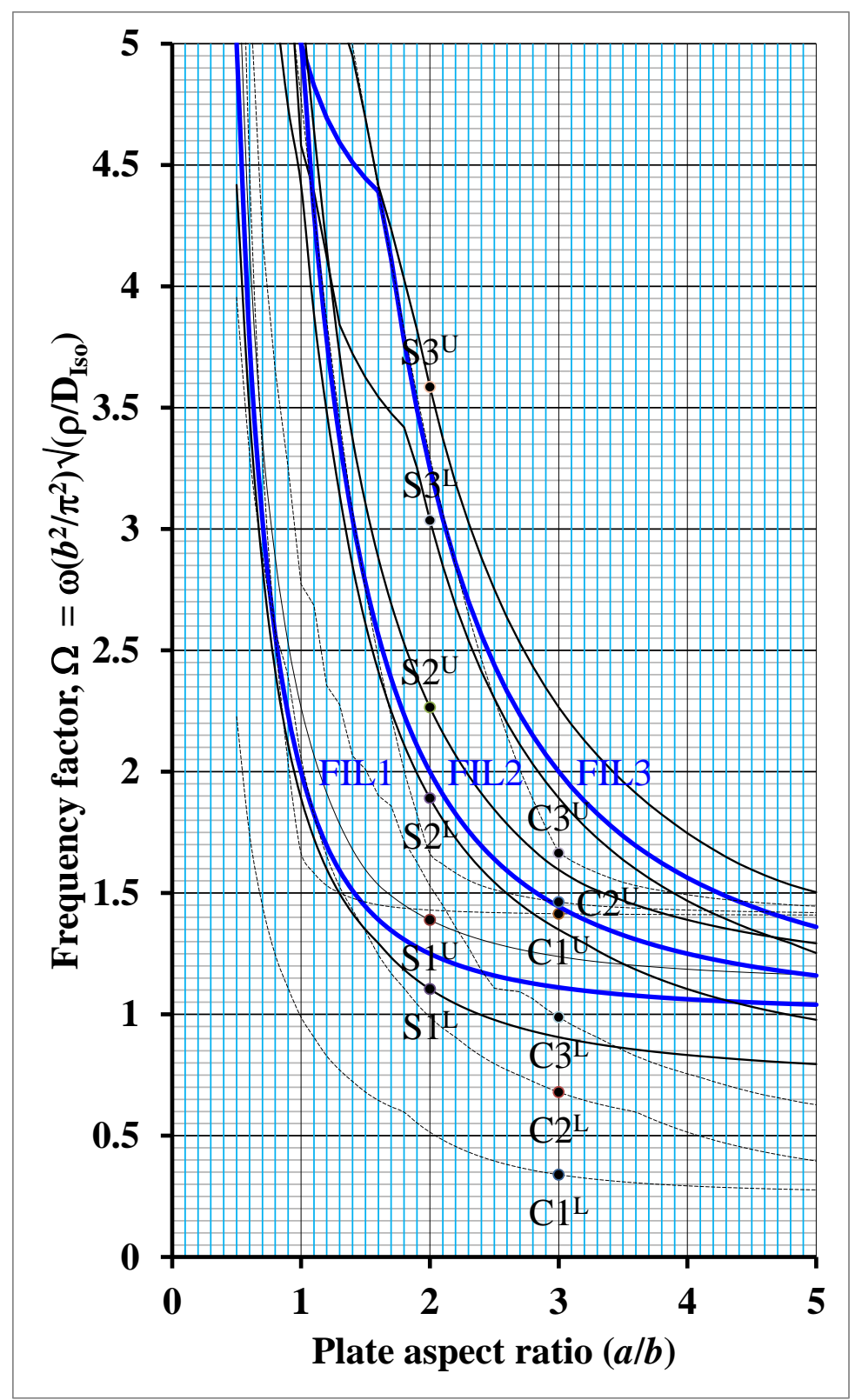

Figure A1 - Natural frequency factor bounds for 12-ply $\mathbf{A}_{S} \mathbf{B}_{l} \mathbf{D}_{\mathrm{S}}$ laminates with Cross-ply, C, laminates (broken lines) and Standard, S, laminates (solid lines). The frequency curves for the equivalent fully isotropic laminate, or FIL, are superimposed for comparison. Numbers following the laminate descriptions $\mathrm{C}$ and $\mathrm{S}$, represent the $1^{\text {st }}, 2^{\text {nd }}$ and $3^{\text {rd }}$ natural frequency factors, with superscripts $\mathrm{L}$ and $\mathrm{U}$ to represent Lower- and Upper-bounds, respectively. 


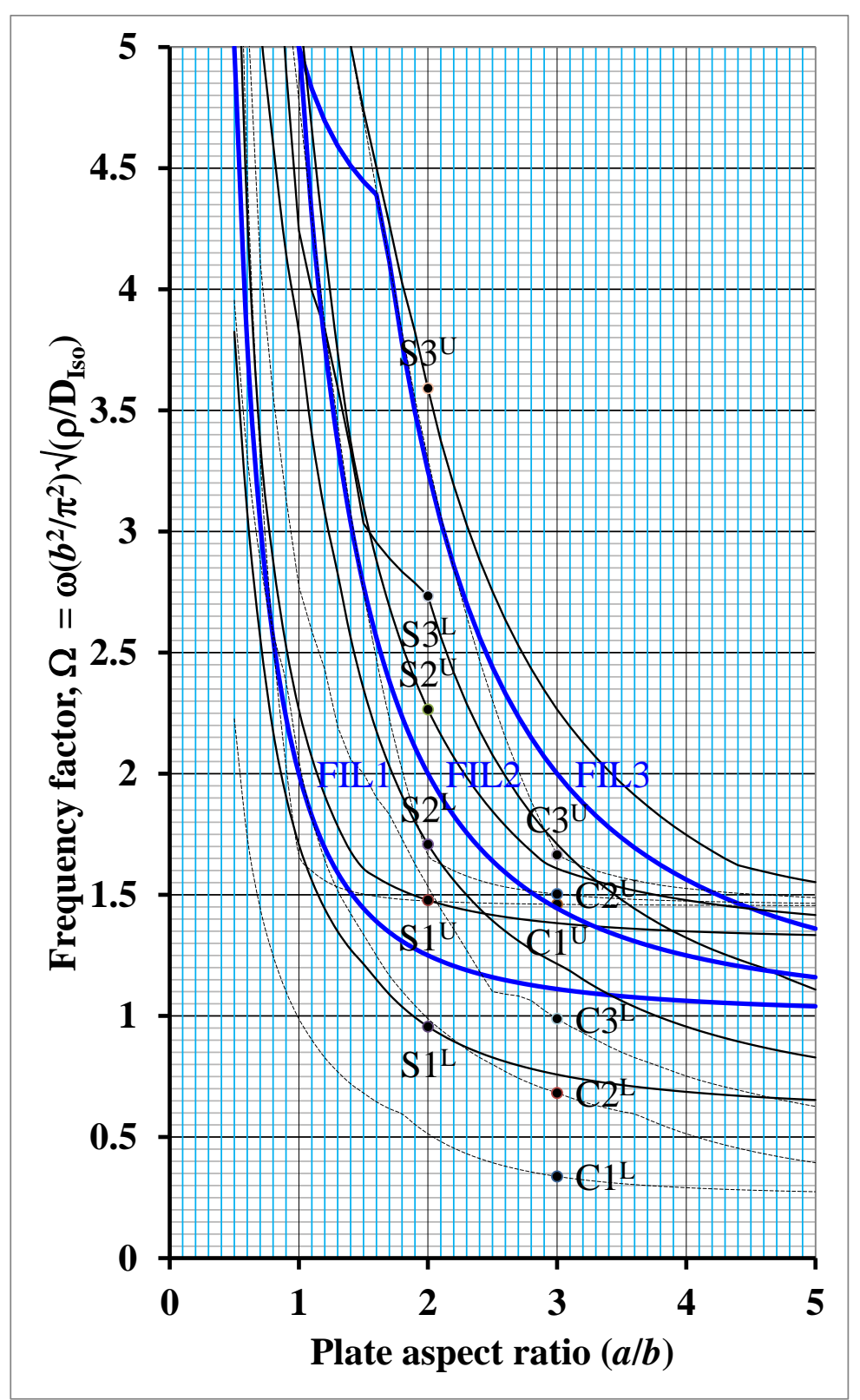

Figure A2 - Natural frequency factor bounds for 16-ply $\mathbf{A}_{\mathrm{S}} \mathbf{B}_{l} \mathbf{D}_{\mathrm{S}}$ laminates with Cross-ply, C, laminates (broken lines) and Standard, S, laminates (solid lines). The frequency curves for the equivalent fully isotropic laminate, or FIL, are superimposed for comparison. Numbers following the laminate descriptions $\mathrm{C}$ and $\mathrm{S}$, represent the Fundamental, $2^{\text {nd }}$ and $3^{\text {rd }}$ natural frequency factors, with superscripts $\mathrm{L}$ and $\mathrm{U}$ to represent Lower- and Upper-bounds, respectively. 


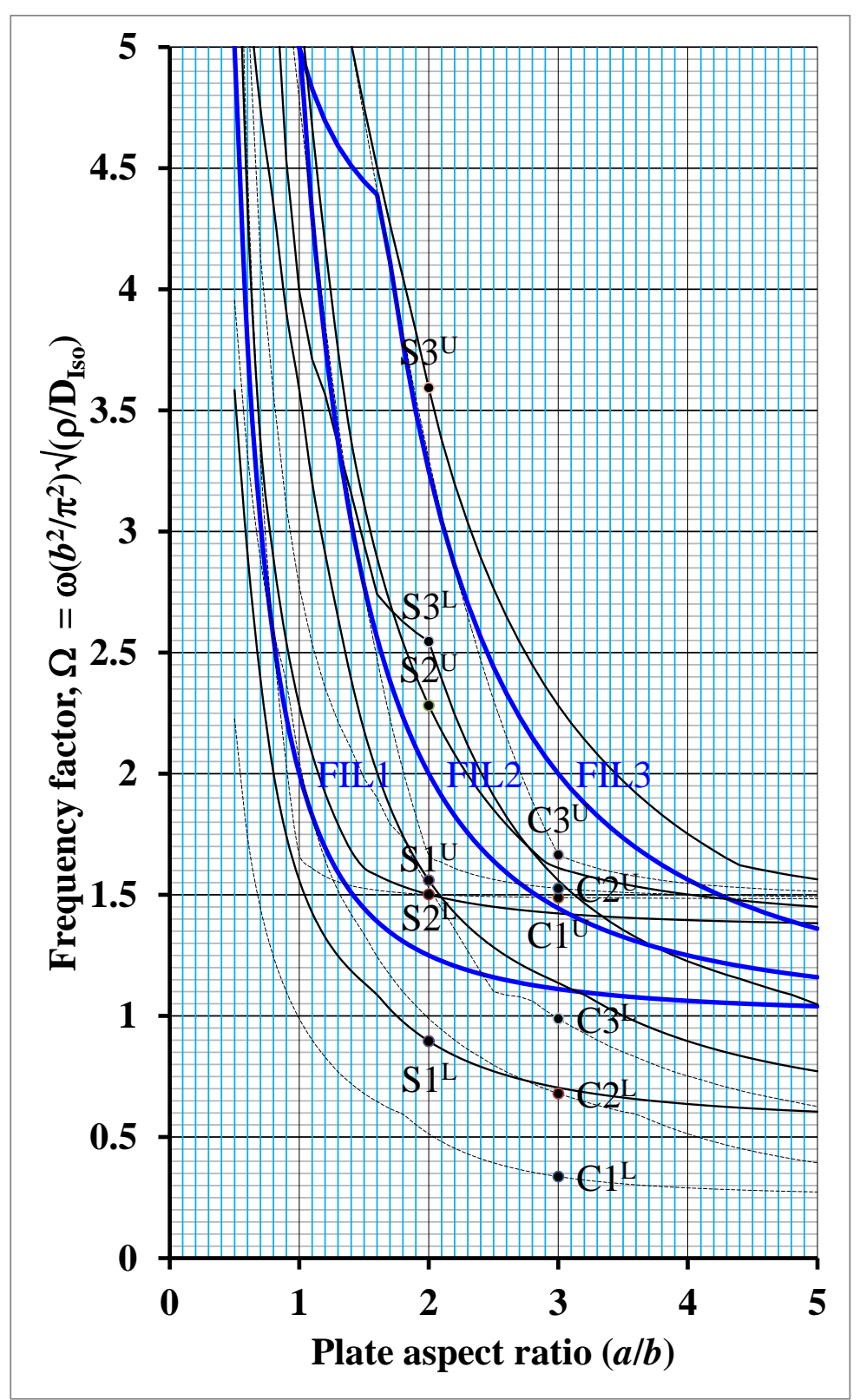

Figure A3 - Natural frequency factor bounds for 20-ply $\mathbf{A}_{\mathrm{S}} \mathbf{B}_{l} \mathbf{D}_{\mathrm{S}}$ laminates with Cross-ply, C, laminates (broken lines) and Standard, S, laminates (solid lines). The frequency curves for the equivalent fully isotropic laminate, or FIL, are superimposed for comparison. Numbers following the laminate descriptions $\mathrm{C}$ and $\mathrm{S}$, represent the Fundamental, $2^{\text {nd }}$ and $3^{\text {rd }}$ natural frequency factors, with superscripts $\mathrm{L}$ and $\mathrm{U}$ to represent Lower- and Upper-bounds, respectively. 